\title{
BMJ Open Electronic nicotine delivery systems and/or electronic non-nicotine delivery systems for tobacco smoking cessation or reduction: a systematic review and meta-analysis
}

Regina El Dib, ${ }^{1,2,3}$ Erica A Suzumura, ${ }^{4}$ Elie A Akl, ${ }^{5,6}$ Huda Gomaa, ${ }^{7}$ Arnav Agarwal, ${ }^{6,8}$ Yaping Chang, ${ }^{6}$ Manya Prasad, ${ }^{9}$ Vahid Ashoorion, ${ }^{6,10}$ Diane Heels-Ansdell, ${ }^{6}$ Wasim Maziak, ${ }^{11}$ Gordon Guyatt ${ }^{6,12}$

To cite: El Dib R, Suzumura EA, Akl EA, et al. Electronic nicotine delivery systems and/or electronic non-nicotine delivery systems for tobacco smoking cessation or reduction: a systematic review and metaanalysis. BMJ Open 2017;7: e012680. doi:10.1136/ bmjopen-2016-012680

- Prepublication history and additional material is available. To view please visit the journal (http://dx.doi.org/ 10.1136/bmjopen-2016012680).

Received 17 May 2016 Revised 7 November 2016 Accepted 19 December 2016

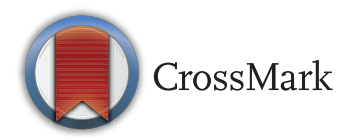

For numbered affiliations see end of article.

Correspondence to Professor Regina El Dib; eldib@fmb.unesp.br $\mathrm{OR}$

eldib@ict.unesp.br

\section{ABSTRACT}

Objective: A systematic review and meta-analysis to investigate the impact of electronic nicotine delivery systems (ENDS) and/or electronic non-nicotine delivery systems (ENNDS) versus no smoking cessation aid, or alternative smoking cessation aids, in cigarette smokers on long-term tobacco use.

Data sources: Searches of MEDLINE, EMBASE, PsycInfo, CINAHL, CENTRAL and Web of Science up to December 2015.

Study selection: Randomised controlled trials (RCTs) and prospective cohort studies.

Data extraction: Three pairs of reviewers

independently screened potentially eligible articles, extracted data from included studies on populations, interventions and outcomes and assessed their risk of bias. We used the Grading of Recommendations Assessment, Development and Evaluation approach to rate overall certainty of the evidence by outcome.

Data synthesis: Three randomised trials including 1007 participants and nine cohorts including 13115 participants proved eligible. Results provided by only two RCTs suggest a possible increase in tobacco smoking cessation with ENDS in comparison with ENNDS (RR 2.03, $95 \% \mathrm{Cl} 0.94$ to $4.38 ; \mathrm{p}=0.07$; $\mathrm{I}^{2}=0 \%$, risk difference (RD) $64 / 1000$ over 6 to 12 months, low-certainty evidence). Results from cohort studies suggested a possible reduction in quit rates with use of ENDS compared with no use of ENDS (OR $0.74,95 \%$ Cl 0.55 to $1.00 ; p=0.051 ; l^{2}=56 \%$, very low certainty).

Conclusions: There is very limited evidence regarding the impact of ENDS or ENNDS on tobacco smoking cessation, reduction or adverse effects: data from RCTs are of low certainty and observational studies of very low certainty. The limitations of the cohort studies led us to a rating of very low-certainty evidence from which no credible inferences can be drawn. Lack of usefulness with regard to address the question of e-cigarettes' efficacy on smoking reduction and cessation was largely due to poor reporting. This

\section{Strengths and limitations of this study}

- Strengths of our review include a comprehensive search; assessment of eligibility, risk of bias and data abstraction independently and in duplicate; assessment of risk of bias that included a sensitivity analysis addressing loss to follow-up; and use of the Grading of Recommendations Assessment, Development and Evaluation approach in rating the certainty of evidence for each outcome.

- The primary limitation of our review is the low certainty consequent on study limitations. Moreover, loss to follow-up was substantial, and our sensitivity analysis demonstrated the vulnerability of borderline effects to missing data. The limitations of the cohort studies led us to a rating of very low-certainty evidence from which no credible inferences can be drawn.

- The small number of studies made it impossible to address our subgroup hypotheses related dose-response of nicotine, more versus less frequent use of e-cigarettes or the relative impact of newer versus older e-cigarette models.

review underlines the need to conduct well-designed trials measuring biochemically validated outcomes and adverse effects.

\section{INTRODUCTION}

Tobacco smokers who quit their habit reduce their risk of developing and dying from tobacco-related diseases. ${ }^{1-4}$ Psychosocial $^{5-7}$ and pharmacological interventions (eg, nicotine replacement therapy (NRT) $)^{5-7}$ increase the likelihood of quitting cigarettes. Even with these aids, however, most smokers fail to quit. 
Electronic nicotine delivery systems (ENDS) and electronic non-nicotine delivery systems (ENNDS) represent a potential third option for those seeking to stop smoking. ENDS are devices that deliver nicotine in an aerosolised form, while ENNDS devices are labelled as not containing nicotine (though labelling may not always be accurate). In theory, these devices as well as the nicotine inhalers may facilitate quitting smoking to a greater degree than other nicotine-based products or no intervention because they deal, at least partly, with the behavioural and sensory aspects of smoking addiction (eg, hand mouth movement). ${ }^{8}$ The debate about the role of ENDS in smoking cessation, however, is compounded by the lack of clear evidence about their value as a smoking cessation tool, their potential to hook tobacco-naive youth on nicotine as well as act as a bridge to combustible tobacco use. ${ }^{9}$ While evidence about all these aspects of ENDS is accumulating, establishing their real place in smoking cessation is essential to outline the public health context of considering them as potential harm-reduced products. There are, however, other reasons for ENDS use such as for relaxation or recreation (ie, the same reason people smoke), with the possibility that adverse health effects may be less than conventional smoking.

There are many types of ENDS. The cigalikes are the first generation of ENDS that provide an appearance of tobacco cigarettes; they are not rechargeable. The second generation of ENDS looks like a pen, allows the user to mix flavours and may contain a prefilled or a refillable cartridge. The third generation of ENDS includes variable wattage devices and are used only with refillable tank systems. The fourth generation contains a large, refillable cartridge and has a tank-style design.

A previous Cochrane systematic review ${ }^{8}$ summarised results from randomised controlled trials (RCTs) and cohort studies. The authors included two RCTs and 11 cohort studies, and concluded that there was evidence to support the potential benefit of ENDS in increasing tobacco smoking cessation. ${ }^{8}$ The certainty of evidence supporting this conclusion was, however, deemed low, primarily due to the small number of trials resulting in wide CIs around effect estimates. ${ }^{8}$ Another systematic review $^{10}$ including a total of six studies (RCTs, cohort and cross-sectional studies) involving 7551 participants concluded that ENDS is associated with smoking cessation and reduction; however, the included studies were heterogeneous, due to different study designs and gender variation. One other review ${ }^{11}$ comparing ecigarettes with other nicotine replacement therapies or placebo included five studies (RCTs and controlled before-after studies) and concluded that participants using nicotine e-cigarettes were more likely to stop smoking, but noted no statistically significant differences. ${ }^{11}$ In a more recent systematic review, Kalkhoran and Glantz ${ }^{9}$ included 20 studies (15 cohort studies, 3 cross-sectional studies and 2 clinical trials), and found $28 \%$ lower odds rates of quitting cigarettes in those who used e-cigarettes compared with those who did not use e-cigarettes; however, the methodological aspects of the observational studies were rated as unclear or high on outcome assessors, and a RCT was rated as high risk of performance and attrition bias.

Previous reviews were, however, limited in that they did not include all studies in this rapidly evolving field, and all but one did not use the Grading of Recommendations Assessment, Development and Evaluation (GRADE) approach to rating quality of evidence. We therefore conducted an updated systematic review of RCTs and cohort studies that assessed the impact of ENDS and/or ENNDS versus no smoking cessation aid or alternative smoking cessation aids on long-term tobacco use, among cigarette smokers, regardless of whether the users were using them as part of a quit attempt.

\section{METHODS}

We adhered to methods described in the Cochrane Handbook for Intervention Reviews. ${ }^{12}$ Our reporting adheres to the preferred reporting items for systematic reviews and meta-analyses (PRISMA) ${ }^{13}$ and meta-analysis of observational studies in epidemiology (MOOSE) statements. ${ }^{14}$ This work was commissioned by the WHO.

\section{Eligibility criteria}

- Study designs: RCTs and prospective cohort studies.

- Participants: cigarette smokers, regardless of whether the users were using them as part of a quit attempt.

- Interventions: ENDS or ENNDS.

- Comparators:

- no smoking cessation aid;

- alternative non-electronic smoking cessation aid, including NRT, behavioural and/or pharmacological cessation aids (eg, bupropion and varenicline) and

- alternative electronic smoking cessation aid (ENDS or ENNDS).

- Outcomes:

- tobacco smoking cessation, with preference to biochemically validated outcomes (eg, carbon monoxide $(\mathrm{CO}))$ measured at 6 months or longer follow-up;

- reduction in cigarette use of at least $50 \%$ and

- serious (eg, pneumonia, myocardial infarction) and non-serious (eg, nausea, vomiting) adverse events measured at 1 week or longer follow-up.

\section{Data source and searches}

A previous Cochrane review with similar eligibility criteria ran a comprehensive search strategy up to July $2014 .^{8}$ Using medical subject headings (MeSH) based on the terms 'electronic nicotine,' 'smoking-cessation,' 'tobacco-use-disorder,' 'tobacco-smoking' and 'quit', we replicated the search strategy of that review ${ }^{8}$ in Medline, EMBASE, PsycInfo, CINAHL, Cochrane Central Register of Controlled Trials (CENTRAL), ISI Web of Science 
and the trial registry (clinicaltrials.gov). The appendix table 1 shows the search strategy for Ovid MEDLINE. This strategy was adapted for the other databases and run from 1 April 2014 to 29 December 2015. We did not impose any language restrictions.

In addition, we established a literature surveillance strategy based on the weekly search alerts by Centers for Disease Control and prevention (CDC)'s Smoking and Health Resource Library of published articles (http:// nccd.cdc.gov/shrl/NewCitationsSearch.aspx) as well as the Gene Borio's daily news items (http://www.tobacco. org). The surveillance strategy started from the time of running the comprehensive literature search up to the time of the submission of this manuscript.

\section{Selection of studies}

Three pairs of reviewers underwent calibration exercises and used standardised pilot tested screening forms. They worked in teams of two and independently screened all titles and abstracts identified by the literature search, obtained full-text articles of all potentially eligible studies and evaluated them for eligibility. Reviewers resolved disagreement by discussion or, if necessary, with third party adjudication. We also considered studies reported only as conference abstracts. For each study, we cite all articles that used data from that study.

\section{Data extraction}

Reviewers underwent calibration exercises, and worked in pairs to independently extract data from included studies. They resolved disagreement by discussion or, if necessary, with third party adjudication. They abstracted the following data using a pretested data extraction form: study design; participants; interventions; comparators; outcome assessed and relevant statistical data. When available, we prioritised $\mathrm{CO}$ measurements as evidence of quitting. When $\mathrm{CO}$ measurement was unavailable, we used self-report measures of quitting.

\section{Risk of bias assessment}

Reviewers, working in pairs, independently assessed the risk of bias of included RCTs using a modified version of the Cochrane Collaboration's instrument ${ }^{15}$ (http:/distillercer.com/resources/). ${ }^{16}$ That version includes nine domains: adequacy of sequence generation, allocation sequence concealment, blinding of participants and caregivers, blinding of data collectors, blinding for outcome assessment, blinding of data analysts, incomplete outcome data, selective outcome reporting and the presence of other potential sources of bias not accounted for in the previously cited domains. ${ }^{16}$

For cohort studies, reviewers independently assessed risk of bias with a modified version of the OttawaNewcastle instrument ${ }^{17}$ that includes confidence in assessment of exposure and outcome, adjusted analysis for differences between groups in prognostic characteristics and missing data. ${ }^{17}$ For incomplete outcome data in individual studies (RCTs and prospective cohort studies), we stipulated as low risk of bias for loss to follow-up of $<10 \%$ and a difference of $<5 \%$ in missing data between intervention/exposure and control groups.

When information regarding risk of bias or other aspects of methods or results was unavailable, we attempted to contact study authors for additional information.

\section{Certainty of evidence}

We summarised the evidence and assessed its certainty separately for bodies of evidence from RCTs and cohort studies. We used the GRADE methodology to rate certainty of the evidence for each outcome as high, moderate, low or very low. ${ }^{18}$ In the GRADE approach, RCTs begin as high certainty and cohort studies as low certainty. Detailed GRADE guidance was used to assess overall risk of bias, ${ }^{19}$ imprecision, ${ }^{20}$ inconsistency, ${ }^{21}$ indirectness $^{22}$ and publication bias ${ }^{23}$ and to summarise results in an evidence profile. We planned to assess publication bias through visual inspection of funnel plots for each outcome in which we identified 10 or more eligible studies; however, we were not able to because there were an insufficient number of studies to allow for this assessment. Cohort studies can be rated up for a large effect size, evidence of dose-response gradient or if all plausible confounding would reduce an apparent effect. ${ }^{24}$

\section{Data synthesis and statistical analysis}

We analysed all outcomes as dichotomous variables. In three-arm studies, we combined results from arms judged to be sufficiently similar (eg, Caponnetto $2013,{ }^{25}$ two arms with similar ENDS regimens: $7.2 \mathrm{mg}$ ENDS and $7.2 \mathrm{mg}$ ENDS plus $5.4 \mathrm{mg}$ ENDS). When studies reported results for daily or intensive use of ENDS separately from non-daily or less intensive use, we included only the daily/intensive use in the primary pooled analysis (eg, Brose $2015,{ }^{26-28}$ we excluded patients with nondaily users; and Biener and Hargraves, ${ }^{29}$ we excluded patients with intermittent defined use). We conducted a sensitivity analysis in which we included all ENDS users, daily/intensive and intermittent/less intensive use. For this analysis, when necessary, we assumed a correlation of 0.5 between the effects in the daily/intensive and intermittent/less intensive groups.

We synthesised the evidence separately for bodies of evidence from RCTs and cohort studies. For RCTs, we calculated pooled Mantel-Haenszel risk ratios (RRs) and associated 95\% CIs using random effects models. For observational studies, we pooled adjusted ORs using random effects models.

After calculating pooled relative effects, we also calculated absolute effects and 95\% CI. For each outcome, we multiplied the pooled RR and its $95 \%$ CI by the median probability of that outcome. We obtained the median probability from the control groups of the available randomised trials. We planned to perform separate analyses for comparisons with interventions consisting of ENDS and/or ENNDS and each type of control interventions with known different effects (no smoking cessation aid; alternative 
Table 1 Study characteristics related to design of study, setting, number of participants, mean age, gender, inclusion and exclusion criteria, and follow-up.

\begin{tabular}{|c|c|c|c|c|c|c|c|c|}
\hline Author, year & $\begin{array}{l}\text { Design of } \\
\text { study }\end{array}$ & Location & $\begin{array}{l}\text { No.*} \\
\text { participants }\end{array}$ & Mean age & $\begin{array}{l}\text { No. male } \\
(\%)\end{array}$ & Inclusion criteria & Exclusion criteria & $\begin{array}{l}\text { Follow-up } \\
\text { (months) }\end{array}$ \\
\hline \multicolumn{9}{|c|}{ Randomized controlled trials } \\
\hline $\begin{array}{l}\text { Adriaens, } \\
2014^{30}\end{array}$ & $\begin{array}{l}\text { Parallel } \\
\text { RCT }\end{array}$ & Leuven, Belgium & 50 & $\begin{array}{l}\text { ENDS1: } 44.7 \\
\text { ENDS2: } 46.0 \\
\text { ENDS and e-liquid**: } 40.3\end{array}$ & $21(43.7)$ & $\begin{array}{l}\text { Being a smoker for at least three years; } \\
\text { smoking a minimum of } 10 \text { factory-made } \\
\text { cigarettes per day and not having the intention } \\
\text { to quit smoking in the near future, but willing to } \\
\text { try out a less unhealthy alternative }\end{array}$ & $\begin{array}{l}\text { Self-reported diabetes; severe } \\
\text { allergies; asthma or other } \\
\text { respiratory diseases; psychiatric } \\
\text { problems; dependence on } \\
\text { chemicals other than nicotine, } \\
\text { pregnancy; breast feeding; high } \\
\text { blood pressure; cardiovascular } \\
\text { disease; currently using any kind of } \\
\text { smoking cessation therapy and prior } \\
\text { use of an e-cigarette }\end{array}$ & 8 \\
\hline $\begin{array}{l}\text { Bullen, } \\
2013^{31-36}\end{array}$ & $\begin{array}{l}\text { Parallel } \\
\text { RCT }\end{array}$ & New Zealand & 657 & $\begin{array}{l}16 \mathrm{mg} \text { ENDS: } 43.6 \\
21 \mathrm{mg} \text { patches NRT: } 40.4 \\
\text { ENNDS: } 43.2\end{array}$ & $252(38.3)$ & $\begin{array}{l}\text { Aged } 18 \text { years or older; had smoked ten or } \\
\text { more cigarettes per day for the past year; } \\
\text { wanted to stop smoking; and could provide } \\
\text { consent }\end{array}$ & $\begin{array}{l}\text { Pregnant and breastfeeding women; } \\
\text { people using cessation drugs or in } \\
\text { an existing cessation programme; } \\
\text { those reporting heart attack, stroke, } \\
\text { or severe angina in the previous } \\
\text { two weeks; and those with poorly } \\
\text { controlled medical disorders, } \\
\text { allergies, or other chemical } \\
\text { dependence }\end{array}$ & 6 \\
\hline $\begin{array}{l}\text { Caponnetto, } \\
2013^{25}\end{array}$ & $\begin{array}{l}\text { Parallel } \\
\text { RCT }\end{array}$ & Catania, Italy & 300 & $\begin{array}{l}7.2 \mathrm{mg} \text { ENDS: } 45.9 \\
7.2 \mathrm{mg} \text { ENDS+5.4 mg } \\
\text { ENDS: } 43.9 \\
\text { ENNDS: } 42.2\end{array}$ & $190(63.3)$ & $\begin{array}{l}\text { Smoke } 10 \text { factory made cigarettes per day } \\
\text { (cig/day) for at least the past five years; age } \\
18-70 \text { years; in good general health; not } \\
\text { currently attempting to quit smoking or wishing } \\
\text { to do so in the next } 30 \text { days; committed to } \\
\text { follow the trial procedures }\end{array}$ & $\begin{array}{l}\text { Symptomatic cardiovascular } \\
\text { disease; symptomatic respiratory } \\
\text { disease; regular psychotropic } \\
\text { medication use; current or past } \\
\text { history of alcohol abuse; use of } \\
\text { smokeless tobacco or nicotine } \\
\text { replacement therapy, and } \\
\text { pregnancy or breastfeeding }\end{array}$ & 12 \\
\hline \multicolumn{9}{|l|}{ Cohort studies } \\
\hline $\begin{array}{l}\text { Al-Delaimy, } \\
2015^{37}\end{array}$ & Cohort & California, US & 628 & Not reported & $478(47.8)$ & $\begin{array}{l}\text { Residents of California; aged } 18 \text { to } 59 \text { years } \\
\text { who had smoked at least } 100 \text { cigarettes during } \\
\text { their lifetime and are current smokers }\end{array}$ & $\begin{array}{l}\text { Participants who reported that they } \\
\text { "might use e-cig" or changed their } \\
\text { reporting at follow-up, as they did } \\
\text { not represent a definitive group of } \\
\text { users or never-users e-cig and } \\
\text { might overlap with both }\end{array}$ & 12 \\
\hline Biener, $2015^{38}$ & Cohort & $\begin{array}{l}\text { Dallas and } \\
\text { Indianapolis } \\
\text { areas, US }\end{array}$ & 1374 & Not reported & $383(55.2)$ & $\begin{array}{l}\text { Adults smokers residing in the Dallas and } \\
\text { Indianapolis metropolitan areas, who had been } \\
\text { interviewed by telephone and gave permission } \\
\text { to be re-contacted }\end{array}$ & Anyone over 65 years old & 36 \\
\hline $\begin{array}{l}\text { Brose, } \\
2015^{40-42}\end{array}$ & Cohort & $\begin{array}{l}\text { Web-based, } \\
\text { United Kingdom }\end{array}$ & $3891^{\star \star *}$ & $\begin{array}{l}\text { ENDS } \\
\text { Among daily users: } 45.7 \\
\text { Among non-daily users: } 45.2 \\
\text { No ENDS }{ }^{\alpha}: 45.7\end{array}$ & $\begin{array}{l}2,015 \\
(49.6)\end{array}$ & $\begin{array}{l}\text { Members were invited by e-mail to participate } \\
\text { in an online study about smoking and who } \\
\text { answered a screening question about their } \\
\text { past-year smoking status }\end{array}$ & $\begin{array}{l}\text { Baseline pipe or cigar smokers, and } \\
\text { follow-up pipe or cigar smokers or } \\
\text { unsure about smoking status }\end{array}$ & 12 \\
\hline Hajek $2015^{46}$ & Cohort & Europe & 100 & $\begin{array}{l}\text { ENDS: } 41.8 \\
\text { No ENDS: } 39\end{array}$ & $57(57)$ & $\begin{array}{l}\text { All smokers joining the UK Stop Smoking } \\
\text { Services in addition to the standard treatment } \\
\text { (weekly support and stop smoking medications } \\
\text { including NRT and varenicline). }\end{array}$ & No exclusion criteria & 4 weeks $^{\beta}$ \\
\hline
\end{tabular}




\begin{tabular}{|c|c|c|c|c|}
\hline Author, year & $\begin{array}{l}\text { Design of } \\
\text { study }\end{array}$ & Location & $\begin{array}{l}\text { No. }{ }^{*} \\
\text { participants }\end{array}$ & Mean age \\
\hline $\begin{array}{l}\text { Harrington } \\
2015^{46}\end{array}$ & Cohort & US & 979 & $46.0^{\star * \star *}$ \\
\hline $\begin{array}{l}\text { Manzoli, } \\
2015^{43}\end{array}$ & Cohort & $\begin{array}{l}\text { Abruzzo and } \\
\text { Lazio region, Italy }\end{array}$ & 1355 & $\begin{array}{l}\text { ENDS only: } \\
45.2 \\
\text { Tobacco cigarettes only: } \\
44.2 \\
\text { Dual smoking: } 44.3\end{array}$ \\
\hline
\end{tabular}

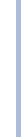

\begin{tabular}{|c|c|c|c|c|}
\hline $\begin{array}{l}\text { Borderud, } \\
2014^{39}\end{array}$ & Cohort & New York, US & 1074 & $\begin{array}{l}\text { ENDS use+ behavioral and } \\
\text { pharmacological treatment: } \\
56.3 \\
\text { No ENDS+behavioral and } \\
\text { pharmacological treatment: } \\
55.6\end{array}$ \\
\hline Prochaska & Cohort & US & 956 & $39.0^{\star \star \star \star}$ \\
\hline
\end{tabular}

$2014^{44}$

Cohort

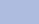

$39.0^{\star \star \star \star}$

\begin{tabular}{l}
$\begin{array}{l}\text { No. male } \\
\text { (\%) }\end{array}$ \\
\hline $525(53.6)$
\end{tabular}

and; cognitively and physically able to

467 (43.5) Patients with cancer referred to a tobacco
478 $(50.0)$

Adult daily smokers (at least 5 cigarettes/day with serious mental illness at four psychiatric hospitals in the San Francisco Bay Area

913 (36.9) Participants from six state quitlines who
Inclusion criteria

Hospitalized cigarette smokers at a tertiary

care medical center; self-identified smoker who

smoked at least one puff in previous 30 days;

English speaking and reading; over age 18 participate in study

757 (55.9) Aged between 30 and 75 years; smoker of e-cig (inhaling at least 50 puffs per week) containing nicotine since six or more months (E-cig only group); smoker of at least one traditional cigarette per day since six or more months (traditional cigarettes only group); smoker of both electronic and traditional cigarettes (at least one per day) since six or more months (mixed Group) cessation program who provided data on their recent (past 30 days) e-cig use

Exclusion criteria

Illicit drug use, breastfeeding or pregnancy, major depression or other psychiatric conditions, severe allergies, active antihypertensive medication, angina pectoris, past episodes of major cardiovascular diseases (myocardial infarction, stroke/TIA, congestive heart failure, COPD, cancer of the lung,

esophagus, larynx, oral cavity, bladder, pancreas, kidney, stomach, cervix, and myeloid leukemia No exclusion criteria

Non-English speaking; medical contraindications to NRT use (pregnancy, recent myocardial infarction); and lack of capacity to consent as determined by a 3 -item screener of study purpose, risks, and benefits

No exclusion criteria

\section{$2,758^{\epsilon}$ \\ Used ENDS one month or more: 48.1 \\ Used ENDS less than one month: 45.3 No ENDS: 49.6 registered for tobacco cessation services. Adult tobacco users, consented to evaluation follow-up, spoke English, provided a valid phone number, and completed at least one intervention call \\ $2013^{45}$}

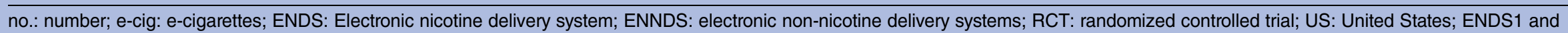
ENDS2: the e-cig groups received the e-cig and four bottles of e-liquid at session 1 (group e-cig1 received the "Joyetech eGo-C" and group e-cig2 received the "Kanger T2-CC"); at session 2, participants' empty bottles were replenished up to again four bottles and at session 3 , they were allowed to keep the remaining bottles.

${ }^{*}$ Randomized or at baseline

${ }^{* *}$ For the first two months control group consisted of no e-cigarettes use. After that period, the participants of control group received the e-cig and e-liquid. ENDS1="Joyetech eGo-C" e-cig and ENDS2="Kanger T2-CC" e-cig.

${ }_{* * *}$ The 4117 were reported in a publication that focused on baseline characteristics, not on the use of e-cigarettes and changes in smoking behavior, so the remaining 53 participants are irrelevant to this review.

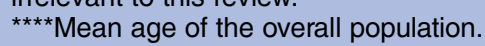

${ }^{\alpha}$ The comparator comprises of current non-users of e-cig, which included never-users and those who had previously tried but were not using at the moment.

${ }^{\beta}$ Hajek 2015 was the only study that entered in the review due to meet the criteria for adverse events.

'But only 2,476 asnwered the question "Have you ever used e-cigarettes, electronic, or vapor cigarettes?" 
non-electronic smoking cessation aid including NRT and alternative electronic smoking cessation aid (ENDS or ENNDS)). For meta-analyses, we used 6 months data or the nearest follow-up to 6 months available.

For dealing with missing data, we used complete case as our primary analysis; that is, we excluded participants with missing data. If results of the primary analysis achieved or approached statistical significance, we conducted sensitivity analyses to test the robustness of those results. Specifically, we conducted a plausible worst-case sensitivity analysis in which all participants with missing data from the arm of the study with the lower quit rates were assumed to have three times the quit rate as those with complete data, and those with missing data from the other arm were assumed to have the same quit rate as participants with complete data. ${ }^{30} 31$

We assessed variability in results across studies by using the $\mathrm{I}^{2}$ statistic and the p-value for the $\chi^{2}$ test of heterogeneity provided by Review Manager. We used Review Manager (RevMan) (V.5.3; Nordic Cochrane Centre, Cochrane) for all analyses. ${ }^{32}$

\section{RESULTS}

\section{Study selection}

Figure 1 presents the process of identifying eligible studies, including publications in the last systematic review, ${ }^{8}$ citations identified through search in electronic databases and studies identified through contact with experts in the field. Based on title and abstract screening, we assessed 69 full texts of which we included 19 publications describing three RCTs involving 1007 participants ${ }^{25}{ }^{33-39}$ and nine cohort studies with a total of 13115 participants. ${ }^{26-29} 40-46$ The interobserver agreement for the full-text screening was substantial (kappa 0.73).

We contacted the authors of the 12 included studies, 9 of whom ${ }^{26-29} 3341434446$ supplied us with all requested data; authors of further 3 studies ${ }^{25} 4246$ did not supply the requested information (see online supplementary appendix table S2).

\section{Study characteristics}

Table 1 describes study characteristics related to design of study, setting, number of participants, mean age, gender, inclusion and exclusion criteria and follow-up.

Five studies ${ }^{25-28} 33 \quad 4246$ were conducted largely in Europe, six in the USA, ${ }^{29} 404143-45$ and one in New Zealand ${ }^{34-39}$ Randomised trials sample size ranged from $50^{33}$ to $657,{ }^{34-39}$ and observational studies from $100^{46}$ to $3891 .^{26-28}$ Typical participants were women in their $40 \mathrm{~s}$ and $50 \mathrm{~s}$. Studies followed participants from 4 weeks ${ }^{46}$ to 36 months. $^{29}$

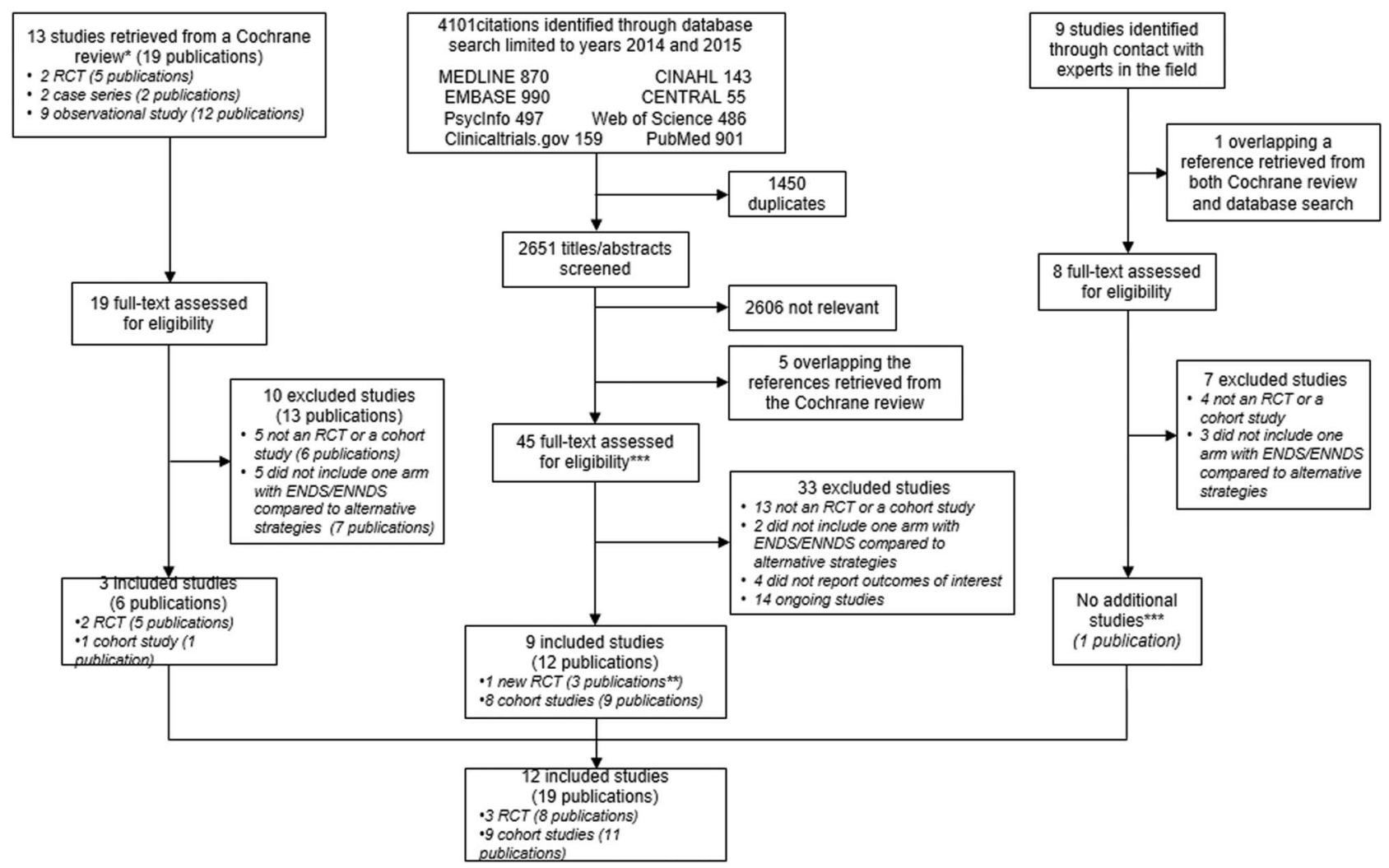

Figure 1 PRISMA diagram of included studies. *McRobbie, $2014 .{ }^{*}{ }^{* \star}$ Further two publications from one RCT included by the Cochrane review were identified only in our search strategy. ${ }^{* \star *}$ Further one publication from one cohort study identified by our search strategy was identified throughout the expert search. 


\section{Author, year Population}

Randomized controlled trials

Adriaens, Participants unwilling to quit $2014^{33}$

smoking (participants from the

control group kept on smoking

regular tobacco cigarettes

during the first eight weeks of

the study)

Bullen, Had smoked ten or more

$2013^{34-39} \quad$ cigarettes per day for the past

year, interested in quitting

Caponnetto, Smokers not intending to quit $2013^{25}$

Yes 0

No 300

Yes 415

No 542

whether the users were using

ENDS as part of a quit attempt

Biener

$2015^{2}$

All respondents had reported being cigarette smokers at

baseline; regardless of whether

the users were using ENDS as part of a quit attempt

Brose, Current smokers; regardless of

$2015^{26-28} \quad$ whether the users were using

ENDS as part of a quit attempt

Hajek, $2015^{46}$ 69\% ( $\left.n=69\right)$ accepted e-cigs as Not reported part of their smoking cessation treatment

Yes $364^{\beta}$

No $331^{\epsilon}$

Not reported

\section{No. ${ }^{*}$ of participants No. ${ }^{*}$ of participants in Description of}

do quit

intervention or exposure

groups and comparator

exposure groups

Yes 0

No 50

ENDS 1: 16

ENDS 2: 17

Control/ENDS: 17

Yes 657

ENDS: 289

NRT: 295

ENNDS: 73

ENDS 1: 100

ENDS 2: 100

ENNDS: 100

No ENDS: 31

ENDS ("Joyetech

eGo-C")

ENDS T2-CC")

ENDS: $236^{\Psi}$

No ENDS: $392^{\Psi}$

ENDS

$1374^{\$}$

ENDS: 1507

No ENDS: 2610

ENDS daily

ENDS non-daily
E-cigarettes ("Kanger

16 mg nicotine ENDS

NRT

NRT

$7.2 \mathrm{mg}$ nicotine ENDS $7.2 \mathrm{mg}$ nicotine ENDS $+5.4 \mathrm{mg}$ nicotine ENDS

ENDS $^{\mathfrak{E}}$ intermittent use ENDS $^{£}$ intensive use

ENDS)

NDS was offered to all No ENDS

smokers in addition to

the standard treatment

(weekly support and stop

smoking medications

including NRT and

varenicline)

ENDS
ENNDS

ENNDS

NDS (used

once or twice

No ENDS

ENDS and

quid $^{\star *}$

Quitting, defined as eCO of

5 ppm or smaller;

questionnaire self-report of

reduction in cigarettes

of $>50 \%$ or complete quitting

Continuous smoking abstinence, biochemically verified (eCO measurement $<10 \mathrm{ppm}$ ); seven day point prevalence abstinence; reduction; and adverse events

Self-report of reduction in cigarettes of $>50 \%$;

abstinence from smoking,

defined as complete

self-reported abstinence

from tobacco smoking - no

even a puff, biochemically verified (eCO measurement $\leq 7 \mathrm{ppm}$ ); and adverse events

Quit attempts; $20 \%$ reduction Duration of abstinence of in monthly no. of cigarettes: one month or longer to and current abstinence from be currently abstinent cigarette use

Smoking cessation; and reduction in motivation to quit smoking among those who had not quit, not otherwise specified

Quit attempts ${ }^{\phi}$; cessation ${ }^{\varpi}$; and substantial reduction defined as a reduction by at least $50 \%$ from baseline CPD to follow-up CPD Self-reported abstinence was biochemically validated by exhaled $\mathrm{CO}$ levels in end-expired breath using a cut-off point on 9ppm, adverse events
Definition of quitters or abstinence

No more cigarette smoking

Abstinence allowing $\leq 5$ cigarettes in total, and proportion reporting no smoking of tobacco cigarettes, not a puff, in the past 7 days

Complete self-reported abstinence from tobacco smoking - not even a puff

Smoking cessation was defined as abstinence from cigarettes for at least one month

Change from being a smoker at baseline to being an ex-smoker at follow-up was coded as cessation

Self-reported abstinence from cigarettes at 4 weeks 


\begin{tabular}{|c|c|c|c|c|c|c|c|}
\hline Author, year & Population & $\begin{array}{l}\text { No.* of participants } \\
\text { intend to quit } \\
\text { smoking }\end{array}$ & $\begin{array}{l}\text { No.* of participants in } \\
\text { intervention or exposure } \\
\text { groups and comparator }\end{array}$ & $\begin{array}{l}\text { Description of } \\
\text { intervention or } \\
\text { exposure groups }\end{array}$ & $\begin{array}{l}\text { Description of } \\
\text { comparators }\end{array}$ & Measured outcomes & $\begin{array}{l}\text { Definition of quitters or } \\
\text { abstinence }\end{array}$ \\
\hline $\begin{array}{l}\text { Harrington, } \\
2015^{45}\end{array}$ & $\begin{array}{l}\text { Hospitalized cigarette smokers. } \\
\text { All were cigarette smokers } \\
\text { initially; regardless of whether } \\
\text { the users were using ENDS as } \\
\text { part of a quit attempt }\end{array}$ & $\begin{array}{l}\text { Yes: } 220^{\star \star \star} \\
\text { No: not reported }\end{array}$ & $\begin{array}{l}\text { ENDS: } 171 \\
\text { No ENDS: } 759\end{array}$ & & & $\begin{array}{l}\text { Quitting smoking based on } \\
\text { 30-day point prevalence at } 6 \\
\text { months }\end{array}$ & $\begin{array}{l}\text { Only self-reported } \\
\text { quitting smoking }\end{array}$ \\
\hline $\begin{array}{l}\text { Manzoli, } \\
2015^{42}\end{array}$ & $\begin{array}{l}\text { Smokers of } \geq 1 \text { tobacco } \\
\text { cigarette/day (tobacco smokers), } \\
\text { users of any type of e-cig, } \\
\text { inhaling } \geq 50 \text { puffs weekly } \\
\text { (e-smokers), or smokers of both } \\
\text { tobacco and e-cig (dual } \\
\text { smokers) }\end{array}$ & Not reported & $\begin{array}{l}\text { ENDS: } 343 \\
\text { Tobacco and ENDS: } 319 \\
\text { Tobacco only: } 693\end{array}$ & $\begin{array}{l}\text { ENDS } \\
\text { Tobacco and ENDS }\end{array}$ & $\begin{array}{l}\text { Tobacco } \\
\text { cigarettes only }\end{array}$ & $\begin{array}{l}\text { Abstinence, proportion of } \\
\text { quitters, biochemically } \\
\text { verified (eCO } \\
\text { measurement>7ppm), } \\
\text { reduce tobacco smoking, } \\
\text { and serious adverse events }\end{array}$ & $\begin{array}{l}\text { Percentage of subjects } \\
\text { reporting sustained ( } 30 \\
\text { days) smoking } \\
\text { abstinence from tobacco } \\
\text { smoking }\end{array}$ \\
\hline $\begin{array}{l}\text { Borderud, } \\
2014^{41}\end{array}$ & $\begin{array}{l}\text { Patients who presented for } \\
\text { cancer treatment and identified } \\
\text { as current smokers (any } \\
\text { tobacco use within the past } 30 \\
\text { days); regardless of whether the } \\
\text { users were using ENDS as part } \\
\text { of a quit attempt }\end{array}$ & $\begin{array}{l}\text { Yes } 633^{*} \\
\text { No } 42^{*}\end{array}$ & $\begin{array}{l}\text { ENDS: } 285 \\
\text { No ENDS: } 789\end{array}$ & $\begin{array}{l}\text { ENDS }^{£}+\text { Evidence-based } \\
\text { behavioral and } \\
\text { pharmacologic treatment }\end{array}$ & $\begin{array}{l}\text { No ENDS } \\
\text { +Evidence-based } \\
\text { behavioral and } \\
\text { pharmacologic } \\
\text { treatment }\end{array}$ & $\begin{array}{l}\text { Smoking cessation by } \\
\text { self-report }\end{array}$ & $\begin{array}{l}\text { Patients were asked if } \\
\text { they had smoked even a } \\
\text { puff of a (traditional) } \\
\text { cigarette within the last } 7 \\
\text { days }\end{array}$ \\
\hline $\begin{array}{l}\text { Prochaska, } \\
2014^{43}\end{array}$ & $\begin{array}{l}\text { Adult daily smokers with serious } \\
\text { mental illness; regardless of } \\
\text { whether the users were using } \\
\text { ENDS as part of a quit attempt }\end{array}$ & $\begin{array}{l}\text { At baseline, } 24 \% \\
\text { intended to quit } \\
\text { smoking in the next } \\
\text { month }\end{array}$ & $\begin{array}{l}\text { ENDS: } 101 \\
\text { No ENDS: } 855\end{array}$ & ENDS & No ENDS & $\begin{array}{l}\text { Smoking cessation by } \\
\text { self-report and, } \\
\text { biochemically verified (CO } \\
\text { and cotinine) }\end{array}$ & $\begin{array}{l}\text { Past } 7 \text { day tobacco } \\
\text { abstinence }\end{array}$ \\
\hline $\begin{array}{l}\text { Vickerman, } \\
2013^{44}\end{array}$ & $\begin{array}{l}\text { Adult tobacco current or past } \\
\text { users; regardless of whether the } \\
\text { users were using ENDS as part } \\
\text { of a quit attempt }\end{array}$ & Not reported & $\begin{array}{l}\text { ENDS: } 765 \\
\text { No ENDS: } 1,711\end{array}$ & $\begin{array}{l}\text { ENDS used for } 1 \text { month } \\
\text { or more } \\
\text { ENDS used for less than } \\
1 \text { month }\end{array}$ & $\begin{array}{l}\text { No ENDS (never } \\
\text { tried) }\end{array}$ & Tobacco abstinence & $\begin{array}{l}\text { Self-reported 30-day } \\
\text { tobacco abstinence at } 7 \\
\text { month follow-up }\end{array}$ \\
\hline \multicolumn{8}{|c|}{ 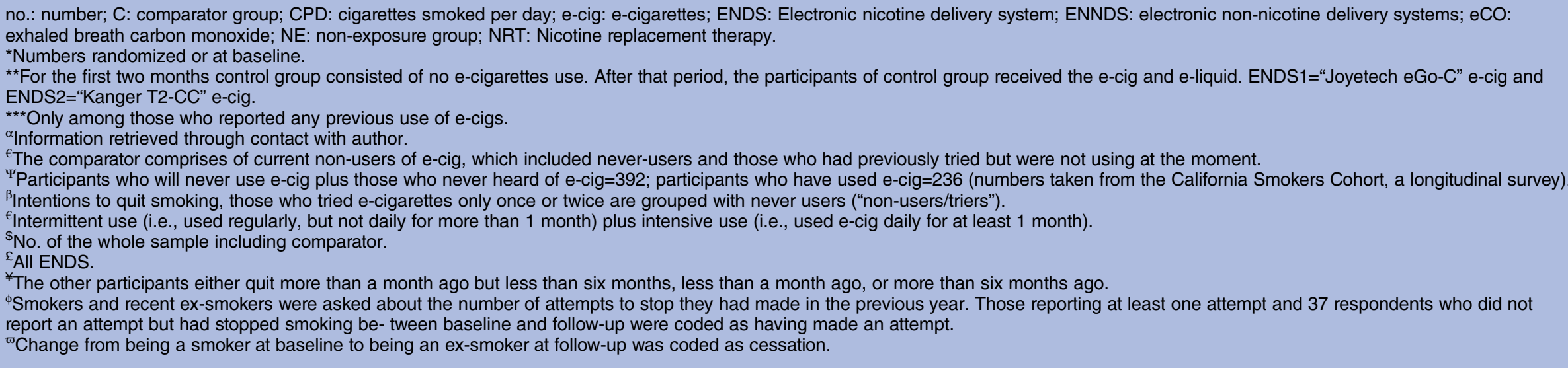 } \\
\hline
\end{tabular}


Table 3 Mean number of conventional cigarettes used per day at baseline and the end of study*

\begin{tabular}{|c|c|c|c|c|c|}
\hline Author, year & Groups & $\begin{array}{l}\text { Mean no. of conventional } \\
\text { cigarettes used per day at } \\
\text { baseline }\end{array}$ & $\begin{array}{l}\text { Mean no. of conventional } \\
\text { cigarettes used per day at } \\
\text { the end of study }\end{array}$ & $\begin{array}{l}\text { Biochemically quitters } \\
\text { (no. of events per no. of } \\
\text { total participants) }\end{array}$ & $\begin{array}{l}\text { Self-reported quitters } \\
\text { (no. of events per no. of } \\
\text { total participants) }\end{array}$ \\
\hline \multirow[t]{3}{*}{ Adriaens, $2014^{33}$} & ENDS 1 & 20.1 & $7.0 \dagger$ & $3 / 13$ & $4 / 13$ \\
\hline & ENDS 2 & 20.6 & $8.1 \dagger$ & $3 / 12$ & $3 / 12$ \\
\hline & Control/ENDS $\ddagger, \S$ & 16.7 & $7.7 \dagger$ & $4 / 13$ & $4 / 13$ \\
\hline \multirow[t]{3}{*}{ Bullen, 2013 $34-39$} & ENDS & 18.4 & 0.79 & $21 / 241$ & Not available \\
\hline & ENNDS & 17.7 & 0.7 & $3 / 57$ & Not available \\
\hline & NRT & 17.6 & $0.8 \rrbracket$ & $17 / 215$ & Not available \\
\hline \multirow{3}{*}{$\begin{array}{l}\text { Caponnetto, } \\
2013^{25}\end{array}$} & $7.2 \mathrm{mg}$ ENDS & $19.0(14.0-25.0)^{\star \star}$ & $12(5.8-20)^{\star \star}, \dagger \dagger$ & Combined ENDS groups: 22/128 & Not available \\
\hline & $\begin{array}{l}7.2 \mathrm{mg} \text { ENDS } \\
\text { plus } 5.4 \mathrm{mg} \\
\text { ENDS }\end{array}$ & $21.0(15.0-26.0)^{\star *}$ & $14(6-20)^{\star \star}, \dagger \dagger$ & & Not available \\
\hline & ENNDS & $22.0(15.0-27.0)^{\star *}$ & $12(9-20)^{\star \star}, \dagger \dagger$ & $4 / 55$ & Not available \\
\hline \multirow{5}{*}{$\begin{array}{l}\text { Al-Delaimy, } \\
2015^{40} \\
\text { Biener, } 2015^{29}\end{array}$} & ENDS & $14.1 \neq \ddagger$ & $13.8 \S \S$ & Not available & $12 / 179$ \\
\hline & ENNDS & & & Not available & $32 / 145$ \\
\hline & $\begin{array}{l}\text { ENDS } \\
\text { intermittent use }\end{array}$ & 16.7ף & Not available & Not available & $\begin{array}{l}\text { Combined ENDS groups: } 42 / \\
331\end{array}$ \\
\hline & $\begin{array}{l}\text { ENDS intensive } \\
\text { use }\end{array}$ & 17.19 & Not available & Not available & \\
\hline & No ENDS & 15.49 & Not available & Not available & $82 / 364$ \\
\hline \multirow[t]{3}{*}{ Brose, $2015^{26-28}$} & ENDS daily users & 14.3 & $13.0^{\star \star \star}$ & Not available & $7 / 86$ \\
\hline & $\begin{array}{l}\text { ENDS non-daily } \\
\text { users }\end{array}$ & 13.5 & $13.9^{\star \star \star}$ & Not available & $25 / 263$ \\
\hline & No ENDS††† & 13.3 & 13.5 & Not available & $168 / 1307$ \\
\hline \multirow[t]{2}{*}{ Hajek, $2015^{46}$} & ENDS & Not available & Not available & 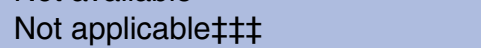 & 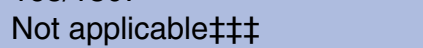 \\
\hline & No ENDS & Not available & Not available & Not applicable $\ddagger \ddagger$ & Not applicable $\ddagger \ddagger \ddagger$ \\
\hline Harrington, & ENDS & 14.1§§§ & $10.3 \S \S \S$ & Not available & $21 / 171$ \\
\hline $2015^{45}$ & No ENDS & $11.9 \S \S \S$ & $9.8 \S \S \S$ & Not available & $62 / 464$ \\
\hline \multirow[t]{3}{*}{ Manzoli, $2015^{42}$} & ENDS only & Not available & 12 & Not available & Not available \\
\hline & $\begin{array}{l}\text { Tobacco } \\
\text { cigarettes only }\end{array}$ & 14.1 & 12.8 & $101 / 491$ & Not available \\
\hline & Dual smoking & 14.9 & 9.3 & $51 / 232$ & Not available \\
\hline \multirow[t]{2}{*}{ Borderud, $2014^{41}$} & ENDS & 13.7 & 12.3 & Not available & $25 / 58$ \\
\hline & No ENDS & 12.4 & 10.1 & Not available & $158 / 356$ \\
\hline
\end{tabular}


Table 3 Continued

\begin{tabular}{|c|c|c|c|c|c|}
\hline Author, year & Groups & $\begin{array}{l}\text { Mean no. of conventional } \\
\text { cigarettes used per day at } \\
\text { baseline }\end{array}$ & $\begin{array}{l}\text { Mean no. of conventional } \\
\text { cigarettes used per day at } \\
\text { the end of study }\end{array}$ & $\begin{array}{l}\text { Biochemically quitters } \\
\text { (no. of events per no. of } \\
\text { total participants) }\end{array}$ & $\begin{array}{l}\text { Self-reported quitters } \\
\text { (no. of events per no. of } \\
\text { total participants) }\end{array}$ \\
\hline \multirow{5}{*}{$\begin{array}{l}\text { Prochaska, } \\
2014^{43} \\
\text { Vickerman, } \\
2013^{44}\end{array}$} & ENDS & 17.0 & 10.0 & $21 / 101$ & Not available \\
\hline & No ENDS & 17.0 & 10.1 & $162 / 855$ & Not available \\
\hline & $\begin{array}{l}\text { ENDS used for } \\
1 \text { month or more }\end{array}$ & 19.4 & 13.5 & Not available & $59 / 273$ \\
\hline & $\begin{array}{l}\text { ENDS used for } \\
\text { less than } 1 \text { month }\end{array}$ & 18.9 & 14.0 & Not available & $73 / 439$ \\
\hline & $\begin{array}{l}\text { No ENDS (never } \\
\text { tried) }\end{array}$ & 18.1 & 12.9 & Not available & $535 / 1711$ \\
\hline
\end{tabular}

${ }^{*}$ When authors provided data for different time points, we presented the data for the longest follow-up.

†8 months from start of intervention.

$\neq$ Control group consisted of received the e-cig and e-liquid (six bottles) for 2 months at the end of session 3 (eight of the 16 participants of the control group received the 'Joyetech eGo-C' and

the remaining eight participants received the 'Kanger T2-CC').

$\S$ For the first 2 months control group consisted of no e-cigarettes use. After that period, the participants of control group received the e-cig and e-liquid. ENDS1='Joyetech eGo-C' e-cig and

ENDS2='Kanger T2-CC' e-cig.

१For those reporting smoking at least one cigarette in past 7 days.

${ }^{* \star}$ Data shown as median and interquartile.

††At 6 months after the last laboratory session.

¥¥Of the 1000 subjects, 993 responded to the question "How many conventional cigarettes smoked per day during the past 30 days".

$\S \S$ Of the 1000 subjects, 881 responded to the question "How many cigarettes smoked per day during the past 30 days."

१ๆ Number of conventional cigarettes used in the prior month at baseline.

$* *$ No. of cigarette per week divided by 7 days.

†††The comparator comprises of current non-users of e-cig which included never-users and those who had previously tried but were not using at the moment.

$\ddagger \ddagger \ddagger$ Not applicable because they followed participants only for 4 weeks, but the study reported adverse events at 1 week or longer.

$\S \S \S$ Data for baseline current e-cig users.

e-cig, eletronic cigarettes; ENDS, electronic nicotine delivery system; ENDS1 and ENDS 2, the e-cig groups received the e-cig and four bottles of e-liquid at session 1 (group e-cig1 received the 'Joyetech eGo-C' and group e-cig2 received the 'Kanger T2-CC'); at session 2; ENNDS, electronic non-nicotine delivery systems; No., number; RYO, roll your own (Ioose tobacco) cigarettes. 


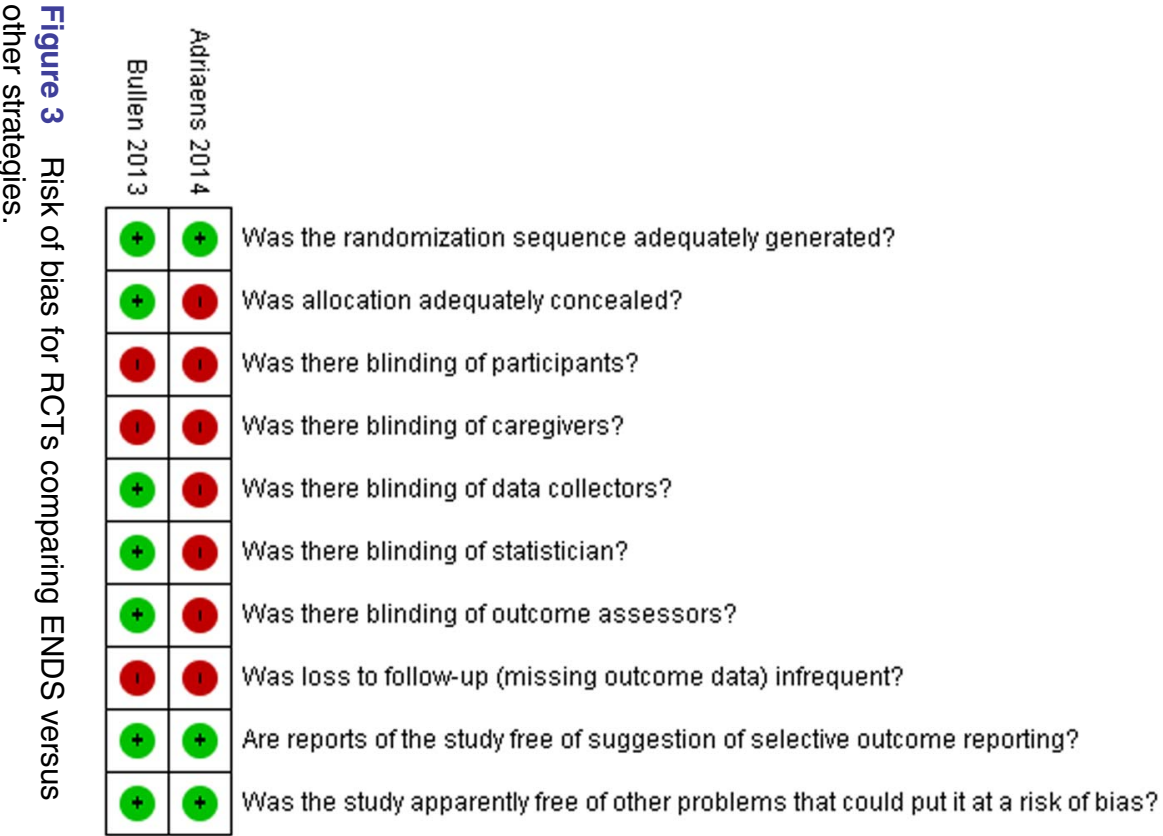

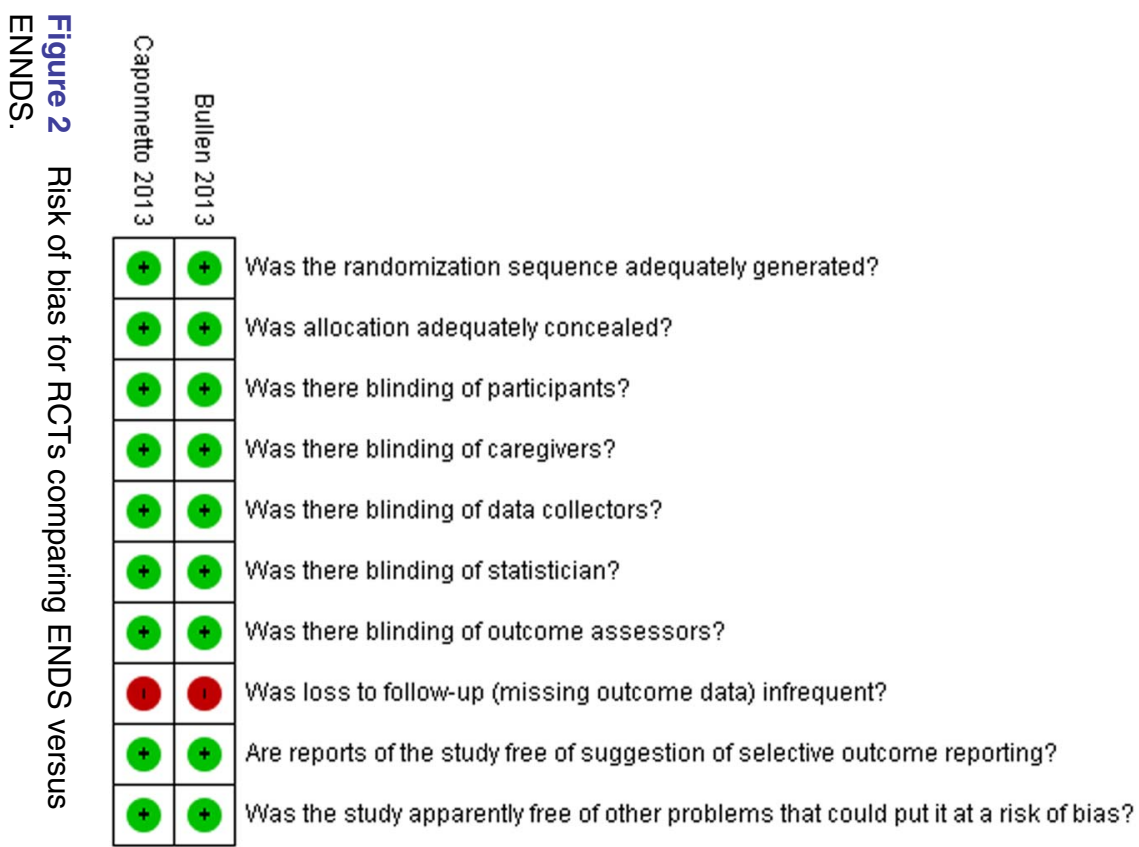

\begin{tabular}{|c|c|c|c|c|c|c|c|c|c|c|}
\hline Author, year & $\begin{array}{l}\text { Was the } \\
\text { randomisation } \\
\text { sequence } \\
\text { adequately } \\
\text { generated? }\end{array}$ & $\begin{array}{l}\text { Was } \\
\text { allocation } \\
\text { adequately } \\
\text { concealed? }\end{array}$ & $\begin{array}{l}\text { Was there } \\
\text { blinding of } \\
\text { participants? }\end{array}$ & $\begin{array}{l}\text { Was there } \\
\text { blinding of } \\
\text { caregivers? }\end{array}$ & $\begin{array}{l}\text { Was there } \\
\text { blinding of } \\
\text { data } \\
\text { collectors? }\end{array}$ & $\begin{array}{l}\text { Was there } \\
\text { blinding of } \\
\text { statistician? }\end{array}$ & $\begin{array}{l}\text { Was there } \\
\text { blinding of } \\
\text { outcome } \\
\text { assessors? }\end{array}$ & $\begin{array}{l}\text { Was loss to } \\
\text { follow-up } \\
\text { (missing } \\
\text { outcome data) } \\
\text { infrequent?* }\end{array}$ & $\begin{array}{l}\text { Are reports of } \\
\text { the study free of } \\
\text { suggestion of } \\
\text { selective } \\
\text { outcome } \\
\text { reporting? }\end{array}$ & $\begin{array}{l}\text { Was the study } \\
\text { apparently free } \\
\text { of other } \\
\text { problems that } \\
\text { could put it at a } \\
\text { risk of bias? }\end{array}$ \\
\hline \multicolumn{11}{|c|}{ Randomised controlled trials assessing ENDS vs ENNDS } \\
\hline $\begin{array}{l}\text { Bullen, } \\
2013^{34-39}\end{array}$ & Definitely yes & Definitely yes & Definitely yes & Definitely yes & Definitely yes & Definitely yes & Definitely yes & Definitely no & Definitely yes & Definitely yes \\
\hline $\begin{array}{l}\text { Caponnetto, } \\
2013^{25}\end{array}$ & Definitely yes & Definitely yes & Definitely yes & Definitely yes & Definitely yes & Definitely yes & Definitely yes & Definitely no & Definitely yes & Definitely yes \\
\hline \multicolumn{11}{|c|}{ Randomised controlled trials assessing ENDS vs other quitting mechanisms } \\
\hline $\begin{array}{l}\text { Adriaens, } \\
2014^{33}\end{array}$ & Definitely yes & Probably no & Probably no & Probably no & Probably no & Probably no & Probably no & Definitely no & Probably yes & Probably yes \\
\hline $\begin{array}{l}\text { Bullen, } \\
2013^{34-39}\end{array}$ & Definitely yes & Definitely yes & Definitely no & Definitely no & Probably yes & Probably yes & Definitely yes & Definitely no & Definitely yes & Definitely yes \\
\hline
\end{tabular}




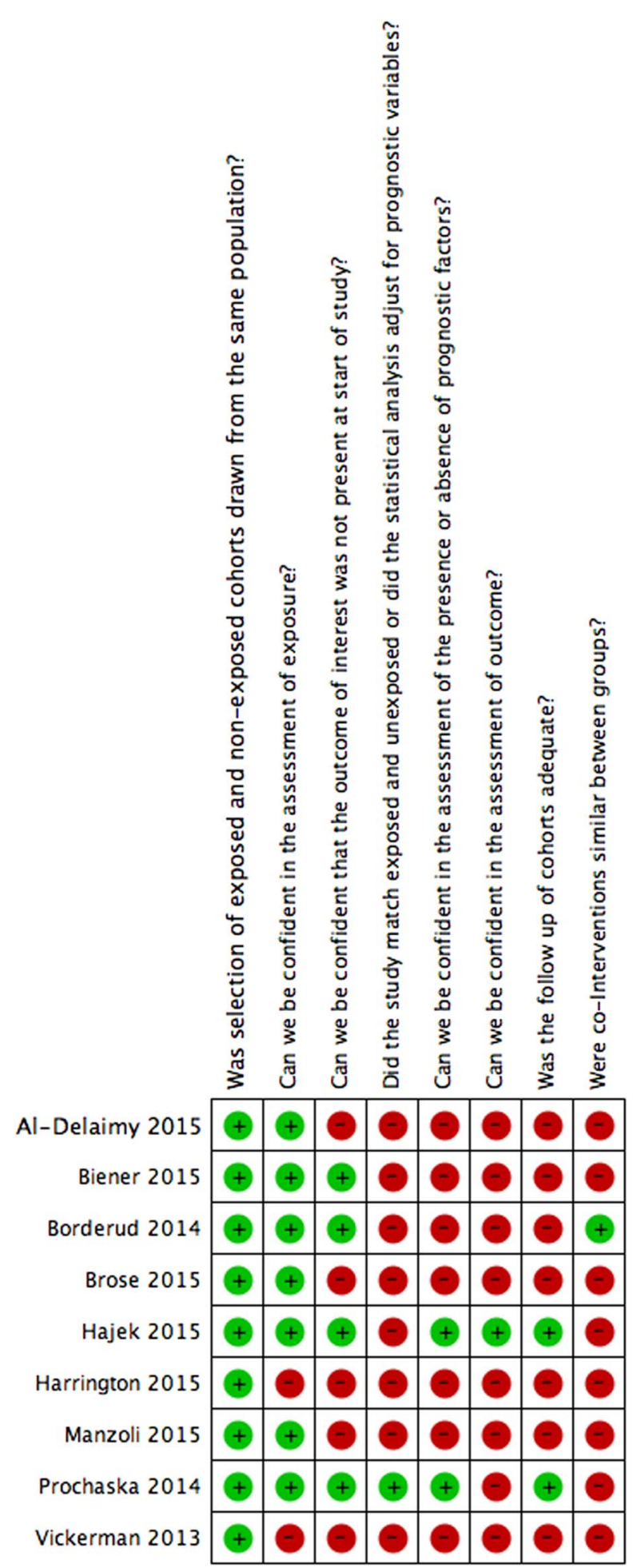

Figure 4 Risk of bias for cohort studies.

Table 2 describes study characteristics related to population, intervention or exposure groups, comparator and assessed outcomes.

Of the three RCTs, one compared ENDS with NRT and ENNDS, ${ }^{34-39}$ another compared different concentrations of ENDS with ENNDS ${ }^{25}$ and the third compared different types of ENDS. ${ }^{33}$ Only the Borderud study ${ }^{41}$ included participants who were also currently receiving other behavioural and pharmacologic treatment. The participants from Vickerman $2013^{44}$ study were all enrolled in a state quitline programme that provided behavioural treatment and in some cases NRT. All nine cohort studies $^{26-29}{ }^{34-46}$ compared ENDS with no use of ENDS $^{26-29} 4041$ or tobacco cigarettes only; ${ }^{42}$ in one, ${ }^{41}$ exposure and non-exposure groups received behavioural and other pharmacologic treatment.

Table 3 describes the mean number of conventional cigarettes used per day at baseline and the end of study.

The mean number at baseline ranged from 11.9 in the no ENDS group ${ }^{45}$ to 20.6 in the ENDS group. ${ }^{33}$ In only two studies ${ }^{26-28} 45$ the mean number of conventional cigarettes used per day presented a reduction from the baseline to the end of study in the ENDS group compared with the no ENDS groups, mainly in the daily users. ${ }^{26-28}$ No included study addressed users of combustible tobacco products other than cigarettes.

Online supplementary appendix table S3 presents the types of e-cigarettes used in the included studies. The three RCTs ${ }^{25} 33$ 36-39 evaluated only ENDS-type cigalikes. A total of $23.7 \%$ of the participants from Brose $2015^{26-28}$ study used tank and in the Hajek $2015^{46}$ study participants used either cigalike or tank. The remaining studies did not report the type of ENDS used.

\section{Risk of bias}

Figures 2 and 3, and table 4, describe the risk of bias assessment for the RCTs.

The major issue regarding risk of bias in the RCTs of ENDS versus ENNDS was the extent of missing outcome data. $^{25}$ 34-39 RCTs comparing ENDS with other nicotine replacement therapies had additional problems of concealment of randomisation ${ }^{33}$ and blinding. ${ }^{33-39}$

Figure 4 and table 5 describe the risk of bias assessment of the cohort studies.

Seven $^{26-29} 40-424445$ of nine cohort studies were rated as high risk of bias for limitations in matching exposed and unexposed groups or adjusting analysis for prognosis variables; confidence in the assessment of the presence or absence of prognostic factors; confidence in the assessment of outcome and similarity of cointerventions between groups; all studies suffered from high risk of bias for missing outcome data.

\section{Outcomes}

The mean number of conventional cigarettes/tobacco products used per day at the end of the studies ranged from $0.7^{34-39}$ in ENDS and ENNDS groups to $13.9^{26-28}$ among non-daily users of ENDS (table 3 ). The three RCTs $^{25}$ 33-39 and one cohort study ${ }^{42}$ biochemically confirmed nicotine abstinence while the others presented only self-reported data ${ }^{26-29} 404143-45$ (table 3).

\section{Tobacco cessation smoking}

Synthesised results from RCTs

Results from two RCTs ${ }^{25}$ 34-39 suggest a possible increase in smoking cessation with ENDS in comparison with 
Table 5 Risk of bias assessment of the cohort studies

\begin{tabular}{|c|c|c|c|c|c|c|c|c|}
\hline $\begin{array}{l}\text { Author, } \\
\text { year }\end{array}$ & $\begin{array}{l}\text { Was selection of } \\
\text { exposed and } \\
\text { non-exposed } \\
\text { cohorts drawn } \\
\text { from the same } \\
\text { population?* }\end{array}$ & $\begin{array}{l}\text { Can we be } \\
\text { confident in } \\
\text { the } \\
\text { assessment of } \\
\text { exposure?t }\end{array}$ & $\begin{array}{l}\text { the outcome } \\
\text { of interest } \\
\text { was not } \\
\text { present at } \\
\text { start of } \\
\text { study? } ¥\end{array}$ & $\begin{array}{l}\text { associated with the } \\
\text { outcome of interest } \\
\text { or did the statistical } \\
\text { analysis adjust for } \\
\text { these prognostic } \\
\text { variables?§ }\end{array}$ & $\begin{array}{l}\text { confident in the } \\
\text { assessment of } \\
\text { the presence or } \\
\text { absence of } \\
\text { prognostic } \\
\text { factors?ๆ }\end{array}$ & $\begin{array}{l}\text { Can we be } \\
\text { confident in } \\
\text { the } \\
\text { assessment of } \\
\text { outcome?** }\end{array}$ & $\begin{array}{l}\text { Was the } \\
\text { follow-up of } \\
\text { cohorts } \\
\text { adequate?t† }\end{array}$ & $\begin{array}{l}\text { Were } \\
\text { cointerventions } \\
\text { similar between } \\
\text { groups?ł‡ }\end{array}$ \\
\hline $\begin{array}{l}\text { Al-Delaimy } \\
2015^{40}\end{array}$ & Definitely yes & Probably yes & Definitely yes & Definitely no & Definitely no & Definitely no & Definitely no & Probably no \\
\hline $\begin{array}{l}\text { Biener } \\
2015^{29}\end{array}$ & Definitely yes & Probably yes & Definitely yes & Definitely no & Definitely no & Definitely no & Definitely no & Probably no \\
\hline $\begin{array}{l}\text { Brose } \\
2015^{26-28}\end{array}$ & Definitely yes & Probably yes & Probably no & Definitely no & Definitely no & Definitely no & Definitely no & Probably no \\
\hline $\begin{array}{l}\text { Hajek } \\
2015^{46}\end{array}$ & Probably yes & Probably yes & Probably yes & Definitely no & Probably yes & Probably yes & Probably yes & Probably no \\
\hline $\begin{array}{l}\text { Harrington } \\
2015^{45}\end{array}$ & Definitely yes & Definitely no & Definitely no & Definitely no & Definitely no & Definitely no & Definitely no & Definitely no \\
\hline $\begin{array}{l}\text { Manzoli } \\
2015^{42}\end{array}$ & Definitely yes & Probably yes & Definitely no & Definitely no & Definitely no & Probably no & Definitely no & Probably no \\
\hline $\begin{array}{l}\text { Borderud } \\
2014^{41}\end{array}$ & Definitely yes & Probably yes & Definitely yes & Definitely no & Definitely no & Definitely no & Definitely no & Definitely yes \\
\hline $\begin{array}{l}\text { Prochaska } \\
2014^{43}\end{array}$ & Definitely yes & Probably yes & Definitely yes & Definitely yes & Probably yes & Definitely no & Definitely yes & Probably No \\
\hline $\begin{array}{l}\text { Vickerman } \\
2013^{44}\end{array}$ & Probably yes & Definitely no & Definitely no & Definitely no & Definitely no & Definitely no & Definitely no & Definitely no \\
\hline \multicolumn{9}{|c|}{ 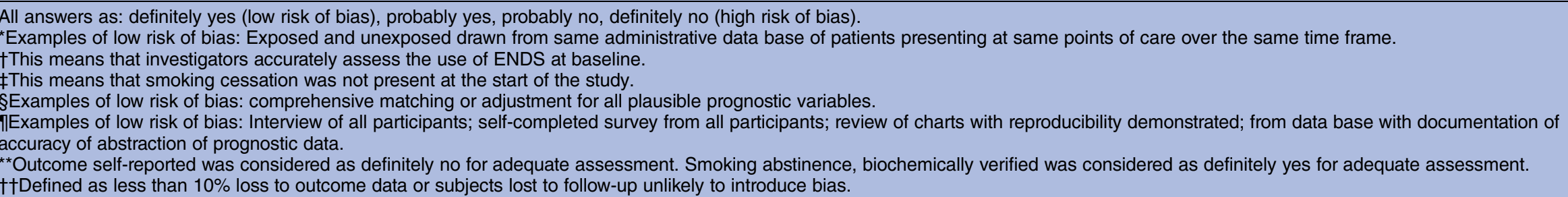 } \\
\hline
\end{tabular}

\section{Did the study}

match exposed and

unexposed for all

Can we be

confident that

the outcome

Was selection

non-exposed

cohorts drawn

exposure?t

start of

study?‡

variables that are

associated with the

or did the statistical

nalysis adjust for

prognostic

factors?ף

Can we be

confident in the

Al-Delaimy Definitely yes

015

$2015^{29}$

Brose

Harrington Definitely yes

$2015^{45}$ 
ENNDS (RR 2.03, 95\% CI 0.94 to 4.38; $\mathrm{p}=0.07 ; \mathrm{I}^{2}=0 \%$, risk difference (RD) $64 / 1000$ over 6 to 12 months, lowquality evidence) (figure 5 , table 6 ).

A plausible worse case sensitivity analysis yielded results that were inconsistent with the primary complete case analysis and fail to show a difference in the effects of ENDS in comparison with ENNDS (RR 1.16, 95\% CI 0.72 to $1.87 ; \mathrm{p}=0.54 ; \mathrm{I}^{2}=0 \%$ ) (see online supplementary appendix figure 1). Certainty in evidence was rated down to low because of imprecision and risk of bias, due to missing outcome data in all studies and lack of blinding of participants, ${ }^{34-39}$ caregivers, data collectors, statistician and outcome assessors in the ENDS versus other NRT studies (figure 2, tables 4 and 6).

Adriaens $2014^{33}$ also compared two types of ENDS and ENDS and e-liquid; results failed to show a difference between the ENDS groups with a very wide CI (RR $1.15,95 \%$ CI 0.28 to $4.76, \mathrm{p}=0.84$ ).

Bullen 2013 $34-39$ also compared ENDS and ENNDS with NRT; results failed to show a difference between these groups with a very wide CI (RR $1.10,95 \%$ CI 0.60 to 2.03, $\mathrm{p}=0.76$ ) and (RR $0.67,95 \%$ CI 0.20 to 2.19, $\mathrm{p}=0.50$ ), respectively.

\section{Synthesised results from cohort studies}

The adjusted OR from primary meta-analysis of eight cohort studies $^{26-29}$ 40-45 comparing ENDS with no ENDS without reported concomitant interventions failed to show a benefit in cessation smoking (OR $0.74,95 \%$ CI 0.55 to $1.00 ; \mathrm{p}=0.051 ; \mathrm{I}^{2}=56 \%$ ) (figure 6 ). A sensitivity analysis from the eight cohort studies ${ }^{26-29}{ }^{40-45}$ using any rather than daily use of ENDS for Brose study, ${ }^{26-28}$ intensive (used e-cigarettes daily for at least 1 month) and intermittent use (used regularly, but not daily for more than 1 month) of ENDS for Biener study ${ }^{29}$ and any use versus never used for Vickerman study ${ }^{44}$ suggested a reduction in cessation smoking rates with ENDS (adjusted OR $0.69,95 \%$ CI 0.53 to $0.91 ; \mathrm{p}=0.01 ; \mathrm{I}^{2}=59 \%$ ) (see online supplementary appendix figure 2 ).

Another sensitivity analysis from the same eight cohort studies ${ }^{26-29} 40-45$ examined whether low and high risk of bias limited to the one characteristic in which the studies differed substantially: confidence in whether the outcome was present at the beginning of the study. Although there were substantial differences in the point estimates in the low risk of bias group (adjusted OR $1.00,95 \%$ CI 0.51 to $1.94 ; p=1.00 ; \mathrm{I} 2=67 \%$ ) and the high risk of bias group (adjusted OR $0.62,95 \%$ CI 0.50 to $0.77 ; \mathrm{p}<0.001 ; \mathrm{I} 2=0 \%$ ), the difference is easily explained by chance (interaction p-value was 0.19) (see online supplementary appendix figure 3 ).

A second sensitivity analysis from the same eight cohort studies $^{26-29} 40-45$ examined whether low and high risk of bias limited to "two or fewer domains rated as low risk of bias' versus 'three or more domains rated as low risk of bias' differed substantially. There were substantial differences in the point estimates between the 'two or fewer domains rated as low risk of bias' group (adjusted OR 0.61, 95\% CI 0.49 to 0.75 ; p $<0.001$; $\mathrm{I} 2=0 \%$ ) and the three or more domains rated as low risk of bias' (adjusted OR 1.26, 95\% CI 0.68 to 2.33; $\mathrm{p}=0.46 ; \mathrm{I} 2=51 \%$ ), with an interaction $\mathrm{p}$-value of 0.03 (see online supplementary appendix figure 4 ).

Certainty in evidence from the observational studies was rated down from low to very low because of risk of bias due to missing outcome data, imprecision in the assessment of prognostic factors and outcomes (figure 4, tables 5 and 7 ), as well as inconsistency in the results.

Borderud $2014^{41}$ reported cessation smoking in 25 out of 58 patients with cancer using ENDS plus behavioural and pharmacologic treatment versus in 158 out of 356 patients with cancer who received only behavioural and pharmacologic treatment (adjusted OR 0.97, 95\% CI 0.71 to 1.33 ).

\section{Reduction in cigarette use of at least $50 \%$}

\section{Synthesised results from RCTs}

Two RCTs ${ }^{25}$ 34-39 results failed to show a difference between ENDS-type cigalikes versus ENNDS group with regards to reduction in cigarettes but with a very wide CI (RR $0.97,95 \%$ CI 0.57 to $1.66 ; \mathrm{p}=0.92 ; \mathrm{I}^{2}=61 \%$ ) (see online supplementary appendix figure 5 ). Certainties in evidence were rated low because of imprecision and risk of bias ${ }^{25} 34-363839$ (figure 2, tables 4 and 6).

\section{Synthesised results from cohort studies}

Two studies ${ }^{26-29}$ suggested increased reduction rates in those with greater versus lesser use of ENDS. Biener ${ }^{29}$ reported an adjusted OR for quitting of 6.07 (95\% CI 1.11 to 33.2) in those with intensive use versus an OR of $0.31(0.04,2.80)$ in those with intermittent use. Brose ${ }^{26-28}$ reported a greater likelihood of substantial reduction (but not quitting) in those with daily use of ENDS (OR

\begin{tabular}{|c|c|c|c|c|c|c|c|}
\hline Study or Subgroup & \multicolumn{2}{|c|}{ ENDS } & \multicolumn{2}{|c|}{ ENNDS } & Weight & $\begin{array}{l}\text { Risk Ratio } \\
\text { M-H, Random, } 95 \% \mathrm{Cl}\end{array}$ & $\begin{array}{l}\text { Risk Ratio } \\
\text { M-H, Random, } 95 \% \mathrm{CI}\end{array}$ \\
\hline Bullen 2013 & 21 & 241 & 3 & 57 & $42.9 \%$ & $1.66[0.51,5.36]$ & \\
\hline Caponnetto 2013 & 22 & 128 & 4 & 55 & $57.1 \%$ & $2.36[0.85,6.54]$ & \\
\hline Total $(95 \% \mathrm{Cl})$ & & 369 & & 112 & $100.0 \%$ & $2.03[0.94,4.38]$ & \\
\hline Total events & 43 & & 7 & & & & \\
\hline \multicolumn{8}{|c|}{\begin{tabular}{llcl} 
Heterogeneity. $\mathrm{Tau}^{2}=0.00 ; \mathrm{Chi}^{2}=0.20, \mathrm{df}=1(\mathrm{P}=0.65) ; \mathrm{l}^{2}=0 \%$ & \multicolumn{1}{l}{$\begin{array}{l}1 \\
\text { Test for overall effect: } \mathrm{Z}=1.80(\mathrm{P}=0.07)\end{array}$} & & $\begin{array}{l}1 \\
\text { Favors ENNDS Favors END }\end{array}$
\end{tabular}} \\
\hline
\end{tabular}

Figure 5 Meta-analysis of RCTs on cessation smoking comparing ENDS versus ENND. 


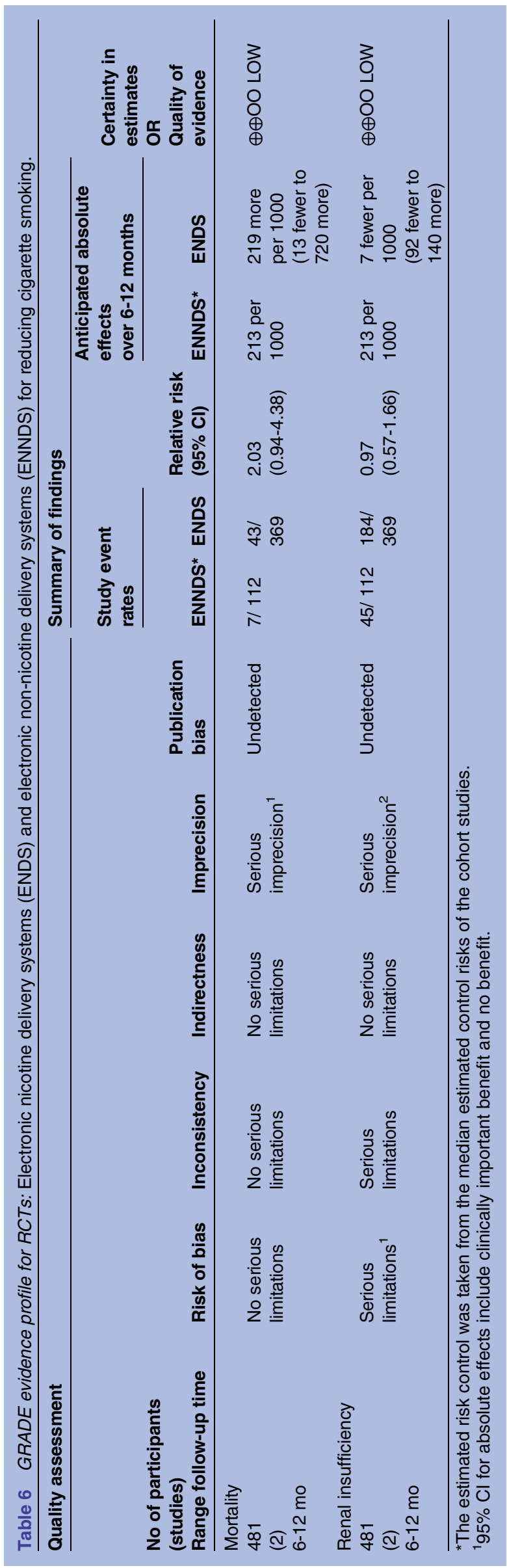

2.49, $95 \%$ CI 1.14 to 5.45 ) but not those with intermittent use (OR 0.850 .43 to 1.71 ).

Adverse effects

Synthesised results from RCTs

The Bullen 2013 ${ }^{34-37} 39$ study reported serious side effects in 27 out of 241 participants in the $16 \mathrm{mg}$ ENDS group and 5 out of 57 for the ENNDS group followed at 6 months; results failed to show a difference between these groups with a very wide CI (OR $1.31,95 \%$ CI 0.48 to $3.57 ; \mathrm{p}=0.59$ ). Results suggested possible increase in side effects in the $21 \mathrm{mg}$ nicotine patches group (14 of 215 ) in comparison with ENDS (OR 1.81, 95\% CI 0.92 to $3.55 ; \mathrm{p}=0.08)$. Serious side effects include death $(\mathrm{n}=1$, in nicotine e-cigarettes group), life threatening illness $(n=1$, in nicotine e-cigarettes group), admission to hospital or prolongation of hospital stay (12\% of all events in nicotine e-cigarettes group, $8 \%$ in patches group and $11 \%$ in placebo e-cigarettes group), persistent or significant disability or incapacity and other medically important events (6\% of all events in nicotine e-cigarettes group, $4 \%$ in patches group and 3\% placebo e-cigarettes group).

Adriaens $2014^{33}$ study reported no serious adverse events in ENDS groups as well as in the e-liquid group at 8 months of follow-up; however at 1 week from start of intervention there were three cases of non-serious adverse events in the ENDS groups.

Caponnetto $2013^{25}$ mentioned that no serious adverse events occurred during the study and authors found a significant reduction in frequency of reported symptoms compared with baseline.

\section{Synthesised results from cohort studies}

Manzoli $^{42}$ reported no significant differences in selfreported serious side effects, but observed four cases of pneumonia, four COPD exacerbations, three myocardial infarctions and one angina as possibly related serious side effects: two among the ENDS users (both switched to tobacco smoking during follow-up); six among tobacco smokers (three quit all smoking) and four among tobacco and ENDS smokers.

Hajek $2015^{46}$ reported one leak irritating a participant's mouth and some reports of irritation at the back of the throat and minor coughing. The remaining studies did not report adverse effects.

\section{DISCUSSION}

\section{Main findings}

Based on pooled data from two randomised trials with 481 participants, we found evidence for a possible increase in tobacco smoking cessation with ENDS in comparison with ENNDS (figure 5). The evidence is, however, of low certainty: the $95 \% \mathrm{CI}$ of the relative risk crossed 1.0 and a plausible worse case sensitivity analysis to assess the risks of bias associated with missing participant data yielded results that were inconsistent with the primary complete case analysis (see online 
supplementary appendix figure 1). Furthermore, in all these RCTs, the ENDS tested were of earlier generation; it is unknown whether providing later generation of ecigarettes or a realistic scenario of allowing users to choose e-cigarettes based on self-preference would have greater benefit. There was no robust evidence of side effects associated with ENDS in the RCTs.

Cohort studies provide very low-certainty evidence suggesting a possible reduction in quit rates with use of ENDS compared with no use of ENDS (figure 6). These studies had a number of limitations: an unknown number of these participants were not using ENDS as a cessation device; some were not using ENDS during a quit attempt; many did not have immediate plans to quit smoking and some may have already failed attempts to stop smoking. In our risk of bias assessment, we judged that seven of nine studies did not have optimal adjustment for prognostic variables. Further, as any cohort study, the results are vulnerable to residual confounding. In particular, use of ENDS may reflect the degree of commitment to smoking cessation, and it may be the degree of commitment, rather than use of ENDS, that is responsible for the change in quit rates. For instance, the finding in two studies that daily use of ENDS, but not intermittent use, increased quit/reduction rates could be interpreted as evidence of the effectiveness of daily use. An alternative interpretation, however, is that those that used ENDS daily were more motivated to stop smoking, and the increased motivation, rather than daily use of ENDS, was responsible for their degree of success. It is worth to mention that motivation to quit smoking is a major determinant of success regardless of the aid used.

In terms of bias against ENDS, cohort studies sometimes enrol smokers already using ENDS and still smoking. Such individuals may already be failing in their attempts to stop smoking. If so, enrolling these participants will underestimate ENDS beneficial effects. Additional concerns with cohort studies include their failure to provide optimal adjustment for prognostic variables or provide data regarding use of alternative smoking reduction aids.

\section{Strengths and limitations}

Strengths of our review include a comprehensive search; assessment of eligibility, risk of bias and data abstraction independently and in duplicate; assessment of risk of bias that included a sensitivity analysis addressing loss to follow-up and use of the GRADE approach in rating the certainty of evidence for each outcome.

The primary limitation of our review is the low certainty consequent on study limitations. We identified only a small number of RCTs with a modest number of participants resulting wide CIs. Moreover, loss to follow-up was substantial, and our sensitivity analysis demonstrated the vulnerability of borderline effects to missing data. The limitations of the cohort studies led us to a rating of very low-certainty evidence from which no credible inferences can be drawn.

Another limitation of this review is the fact that we could not address our hypothesis about increased rates in smoking cessation in those who used e-cigarettes with higher concentrations of nicotine compared with those using less nicotine, or daily e-cigarette users compared with non-daily e-cigarette users, or those who use newer forms of ENDS compared with users of first generation devices due to lack of evidence. However, although these assumptions seems logical, nicotine delivery from ENDS depends on other factors such as the efficiency of the device in aerosolising the liquid and user experience, apart from the concentration of nicotine in the ENDS liquid.

Furthermore, whether or not ENDS are an effective aid in the cessation of smoking may depend on whether the users were using ENDS as part of a quit attempt or not, and this may play an important role also as a possible confounder. Data is not yet available to conduct a subgroup analysis addressing this hypothesis.
Figure 6 Meta-analysis of cohort studies on cessation smoking with adjusted ORs.

$\begin{array}{ll}\text { Study } & \text { Year } \\ \text { Al-Delaimy } & 2015 \\ \text { Biener } & 2015 \\ \text { Borderud } & 2014 \\ \text { Brose } & 2015 \\ \text { Harrington } & 2015 \\ \text { Manzoli } & 2015 \\ \text { Prochaska } & 2014 \\ \text { Vickerman } & 2013\end{array}$

Random Effects Estimate $p=0.051, p=58 \%$ 


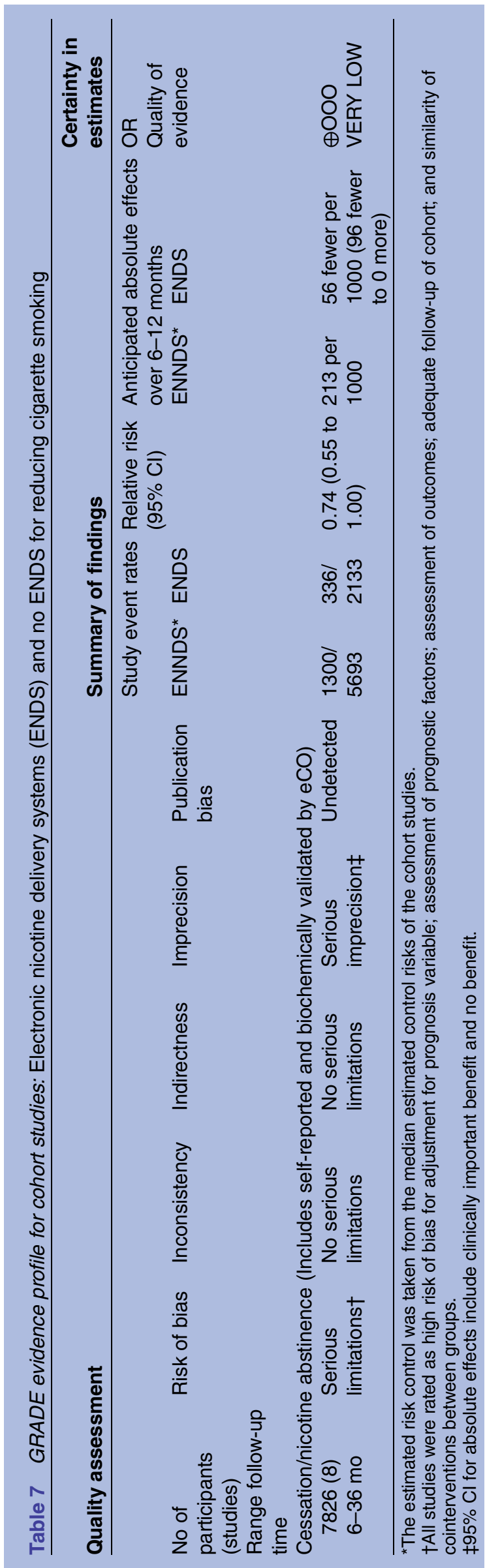

Subsequent trials should help provide information regarding whether their impact on cessation of smoking depends on whether users were intended to quit smoking, as well as the other unresolved issues.

Other limitations of this review were the fact of having insufficient number of included studies to allow the complete statistical analysis that we had planned. We were not able to assess publication bias because there were $<10$ eligible studies addressing the same outcome in a meta-analysis. We also planned to perform subgroup analyses according to the characteristics of:

- participants (commitment to stopping smoking, use of e-cigarettes at baseline);

- interventions (dose of nicotine delivered by the ecigarette, frequency of use of the e-cigarette and type of e-cigarettes) and

- concomitant interventions in e-cigarettes and control groups.

However, we also were not able to conduct these analyses because they did not meet our minimal criteria, which were at least five studies available, with at least two in each subgroup. A final statistical limitation is that we calculated differences from 6 to 12 months of follow-up. Absolute differences may differ across this time frame and constitute a source of variability. Moreover, there are three schools of thought with respect to use of fixed and random effect models: those who prefer always to use fixed effects, those who prefer (almost) always random effects and those who would choose fixed and random depending on the degree of heterogeneity. Each argument has its proponents within the statistical community. The argument in favour of the second rather than the third is 1) there is always some heterogeneity, so any threshold of switching models is arbitrary and 2) when there is little heterogeneity, fixed and random yield similar or identical results, so one might as well commit oneself to random from the start. We find these two arguments compelling; thus, our choice.

Finally, another limitation of the observational studies in this review is the potential for selection bias as the populations compared differ in terms of intention to quit. Furthermore, in all these RCTs, the ENDS tested were earlier generation; it is possible that later generation of e-cigarettes would have greater benefit.

Although this review presents several limitations, the issue is whether one should dismiss these results entirely or consider them bearing in mind the limitations. The latter represent our view of the matter.

\section{Relation to prior work}

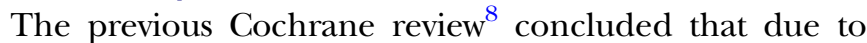
low event rates and wide CIs, only low-certainty evidence was available from studies comparing ENDS with ENNDS. We excluded some studies included in that Cochrane review as they were either case series, crosssectional or did not include one arm with ENDS/ ENNDS compared with alternative strategies. We also included one additional RCT, ${ }^{33}$ and nine new cohort 
studies, ${ }^{26-29} 40-44 \quad 46$ not included in the Cochrane review. The rationale for including the prospective cohort studies in our review was that it was anticipated that the search would return few RCTs. The authors of the Cochrane review found that ENDS is a useful aid to stop smoking long term compared with ENNDS.

Another review ${ }^{10}$ including two of our three RCTs, ${ }^{25}{ }^{34-39}$ and further two case series and two crosssectional studies, assessed the impact of e-cigarettes in achieving smoking abstinence or reduction in cigarette consumption among current smokers who had used the devices for 6 months or more. The authors concluded that e-cigarette use is associated with smoking cessation; these results are similar to our meta-analysis comparing ENDS with ENNDS (figure 5). Khoudigian's 2016 review $^{11}$ reported a non-statistically significant trend toward smoking cessation in adults using nicotine ecigarettes compared with other therapies or placebo. However, the review by Kalkhoran and Glatz $2016^{9}$ concluded that e-cigarettes are associated with significantly less quitting among smokers.

\section{Implications}

Existing smoking reduction aids such as NRT are effective, but their impact is limited: the proportion of those who quit when using these aids remains small. The available evidence, of low or very low quality, can neither verify nor exclude the hypothesis that, because they address nicotine addiction and potentially deal with behavioural and sensory aspects of cigarette use, ENDS may be more effective than other nicotine replacement strategies. This is an important finding, and raises questions regarding how effective it may be addressing the behavioural and sensory aspects of cigarette use in their addictive potential. Thus, the focus of subsequent work should perhaps be on the dose and delivery of nicotine, though teasing out the nicotine effects from sensory aspects is likely to be challenging. It is possible that type of ENDS or dose of exposure may influence quit rates, and that newer models may be more effective, but there is insufficient data to provide insight into these issues. Lack of usefulness with regard to address the question of e- cigarettes' efficacy on smoking reduction and cessation was largely due to poor reporting.

Therefore, owing to the limitations of the studies included in this analysis it is impossible to make strong inferences regarding whether e-cigarette use promotes, has no effect or hinders smoking cessation. This review underlines the need to conduct well-designed trials in this field measuring biochemically validated outcomes and adverse effects.

\footnotetext{
Author affiliations

${ }^{1}$ Department of Anaesthesiology, Botucatu Medical School, UNESP-Univ Estadual Paulista, São Paulo, Brazil

${ }^{2}$ McMaster Institute of Urology, McMaster University, Hamilton, Ontario, Canada

${ }^{3}$ Institute of Science and Technology, Department of Biosciences and Oral Diagnosis, Unesp—Univ Estadual Paulista, São José dos Campos, Brazil
}

${ }^{4}$ Research Institute- Hospital do Coração (HCor), São Paulo, Brazil

${ }^{5}$ Department of Internal Medicine, Clinical Research Institute (CRI), Center for Systematic Reviews in Health Policy and Systems Research (SPARK),

American University of Beirut, Beirut, Lebanon

${ }^{6}$ Department of Clinical Epidemiology \& Biostatistics, McMaster University, Hamilton, Ontario, Canada

${ }^{7}$ Department of Pharmacy, Tanta Chest Hospital, Tanta, Egypt

${ }^{8}$ Faculty of Medicine, University of Toronto, Toronto, Ontario, Canada

${ }^{9}$ Department of Community Medicine, Postgraduate Institute of Medical Sciences, Rohtak, Haryana, India

${ }^{10}$ Isfahan Medical Education Research Centre, Isfahan University of Medical Sciences, Isfahan, Iran

${ }^{11}$ Department of Epidemiology, Robert Stempel College of Public Health and Social Work, Florida International University, Miami, Florida, USA

${ }^{12}$ Department of Medicine, McMaster University, Hamilton, Ontario, Canada

Acknowledgements We would like to thank Dr Karolien Adriaens, Dr Frank Baeyen, Dr Wael Al-Delaimy, Dr Lois Biener, Dr Sarah Borderud, Dr Jamie Ostroff, Dr Chris Bullen and Dr Katrina Vickerman to provide us with additional data; and Dr Norbert Hirschhorn to provide us with the results of weekly search alerts. We also would like to thank Rachel Couban for the search strategy, and Dr Konstantinos Farsalinos, Dr Hayden McRobbie and Dr Kristian Filion for the great inputs during revisions.

Contributors All authors contributed to all aspects of this study, including conducting the literature search, study design, data collection, data analysis, data interpretation and writing of the paper. AUTHORS' CONTRIBUTIONS GG, RED, WM and EAA conceived the review. DH-A undertook the searches. RED, EAS, HG, AA, YC, MP and VA screened search results. EAS organised the retrieval of papers. RED, EAS, HG, AA, YC, MP and VA screened the retrieved papers against inclusion criteria. RED, EAS, HG, AA, YC, MP and VA appraised quality of papers. RED, EAS, HG, AA, YC, MP and VA extracted data from papers. RED wrote to authors of papers for additional information. RED provided additional data about papers. RED and EAS obtained and screened data on unpublished studies. RED managed the data for the review. RED and EAS contributed in entering data into Review Manager (RevMan). RED, EAS, GHG, WM and EAA contributed in analysing RevMan statistical data. RED, EAS, GHG, WM and EAA interpreted the data. RED, EAS, GG, WM and EAA contributed in making statistical inferences. RED, GHG, WM and EAA wrote the review. RED, EAS, HG, AA, YC, MP, VA, EAA, WM and GH took responsibility for reading and checking the review before submission.

Funding The study is funded by a WHO grant.

Disclaimer The funding agencies played no role in the conduct of the research or preparation of the manuscript.

Competing interests Regina El Dib received a Brazilian Research Council (CNPq) scholarship (CNPq 310953/2015-4).

Provenance and peer review Not commissioned; externally peer reviewed.

Data sharing statement No additional data available.

Open Access This is an Open Access article distributed in accordance with the Creative Commons Attribution Non Commercial (CC BY-NC 4.0) license, which permits others to distribute, remix, adapt, build upon this work noncommercially, and license their derivative works on different terms, provided the original work is properly cited and the use is non-commercial. See: http:// creativecommons.org/licenses/by-nc/4.0/

\section{REFERENCES}

1. U.S. Department of Health and Human Services. The health consequences of smoking-50 years of progress: a report of the surgeon general. Atlanta: U.S. Department of Health and Human Services, Centers for Disease Control and Prevention, National Center for Chronic Disease Prevention and Health Promotion, Office on Smoking and Health, 2014 (accessed 21 May 2015).

2. U.S. Department of Health and Human Services. How tobacco smoke causes disease: the biology and behavioral basis for smoking-attributable disease: a report of the surgeon general. Atlanta: U.S. Department of Health and Human Services, Centers for Disease Control and Prevention, National Center for Chronic 
Disease Prevention and Health Promotion, Office on Smoking and Health, 2010 (accessed 21 May 2015).

3. U.S. Department of Health and Human Services. The health consequences of smoking: a report of the surgeon general. Atlanta: U.S. Department of Health and Human Services, Centers for Disease Control and Prevention, National Center for Chronic Disease Prevention and Health Promotion, Office on Smoking and Health, 2004 (accessed 21 May 2015)

4. U.S. Department of Health and Human Services. The health benefits of smoking cessation: a report of the surgeon general. Atlanta: U.S. Department of Health and Human Services, Centers for Disease Control and Prevention, Center for Chronic Disease Prevention and Health Promotion, Office on Smoking and Health, 1990 (accessed 21 May 2015).

5. Tsoi DT, Porwal M, Webster AC. Interventions for smoking cessation and reduction in individuals with schizophrenia. Cochrane Database Syst Rev 2013;2:CD007253.

6. Maziak W, Jawad M, Jawad S, et al. Interventions for waterpipe smoking cessation. Cochrane Database Syst Rev 2015;7: CD005549.

7. van der Meer RM, Wagena E, Ostelo RWJG, et al. Smoking cessation for chronic obstructive pulmonary disease. Cochrane Database Syst Rev 2001;1:CD002999.

8. McRobbie H, Bullen C, Hartmann-Boyce J, et al. Electronic cigarettes for smoking cessation and reduction. Cochrane Database Syst Rev 2014;12:CD010216.

9. Kalkhoran S, Glantz SA. E-cigarettes and smoking cessation in real-world and clinical settings: a systematic review and meta-analysis. Lancet Respir Med 2016;4:116-28.

10. Rahman MA, Hann N, Wilson A, et al. E-cigarettes and smoking cessation: evidence from a systematic review and meta-analysis. PLOS ONE 2015;10:e0122544.

11. Khoudigian S, Devji T, Lytvyn L, et al. The efficacy and short-term effects of electronic cigarettes as a method for smoking cessation: a systematic review and a meta-analysis. Int $J$ Public Health 2016;61:257-67.

12. Higgins JPT, Green S, eds. Cochrane Handbook for Systematic Reviews of Interventions Version 5.1.0 [updated March 2011]. The Cochrane Collaboration, 2011. http://www.cochrane-handbook.org

13. Moher D, Liberati A, Tetzlaff J, et al. Preferred reporting items for systematic reviews and meta-analyses: The PRISMA statement. BMJ 2009;339:b2535.

14. Stroup DF, Berlin JA, Morton SC, et al. Meta-analysis of observational studies in epidemiology: a proposal for reporting Meta-analysis of observational studies in epidemiology (MOOSE) group. JAMA 2000;283:2008-12.

15. Higgins JP, Altman DG, Gøtzsche PC, et al., Cochrane bias methods group, Cochrane statistical methods group. The Cochrane Collaboration's tool for assessing risk of bias in randomised trials. BMJ 2011;343:d5928.

16. Guyatt GH, Busse JW. Modification of Cochrane tool to assess risk of bias in randomized trials. http://distillercer.com/resources/

17. Guyatt GH, Busse JW. Modification of Ottawa-Newcastle to assess risk of bias in nonrandomized trials. http://distillercer.com/resources/

18. Guyatt GH, Oxman AD, Vist GE, et al., GRADE working group. GRADE: an emerging consensus on rating quality of evidence and strength of recommendations. BMJ 2008;336:924-6.

19. Guyatt GH, Oxman AD, Vist G, et al. GRADE guidelines: 4. Rating the quality of evidence-study limitations (risk of bias). $J$ ClinEpidemiol 2011a;64:407-15.

20. Guyatt GH, Oxman AD, Kunz R, et al. GRADE guidelines 6. Rating the quality of evidence-imprecision. $J$ ClinEpidemiol 2011b;64:1283-93.

21. Guyatt GH, Oxman AD, Kunz R, et al., GRADE Working Group. GRADE guidelines: 7. Rating the quality of evidence-inconsistency. J ClinEpidemiol 2011c;64:1294-302.

22. Guyatt GH, Oxman AD, Kunz R, et al., GRADE Working Group. GRADE guidelines: 8. Rating the quality of evidence-indirectness. $J$ ClinEpidemiol 2011d;64:1303-10.

23. Guyatt GH, Oxman AD, Montori V, et al. GRADE guidelines: 5. Rating the quality of evidence-publication bias. J ClinEpidemiol 2011e;64:1277-82.

24. Guyatt $\mathrm{GH}$, Oxman $\mathrm{AD}$, Sultan $\mathrm{S}$, et al., GRADE Working Group. GRADE guidelines: 9 . Rating up the quality of evidence. $J$ Clin Epidemiol 2011;64:1311-6.
25. Caponnetto $\mathrm{P}$, Campagna D, Cibella F, et al. EffiCiency and safety of an electronic cigarette (ECLAT) as tobacco cigarettes substitute: a prospective 12-month randomized control design study. PLOS ONE 2013;8:e66317.

26. Brose LS, Hitchman SC, Brown J, et al. Is the use of electronic cigarettes while smoking associated with smoking cessation attempts, cessation and reduced cigarette consumption? A survey with a 1-year follow-up. Addiction 2015;110: 1160-8.

27. Brown J, West R, Beard E, et al. Prevalence and characteristics of e-cigarette users in Great Britain: findings from a general population survey of smokers. Addict Behav 2014;39:1120-5.

28. Hitchman SC, Brose LS, Brown J, et al. Associations between e-cigarette type, frequency of use, and quitting smoking: findings from a longitudinal online panel survey in Great Britain. Nicotine Tob Res 2015;17:1187-94.

29. Biener L, Hargraves JL. A longitudinal study of electronic cigarette use among a population-based sample of adult smokers: association with smoking cessation and motivation to quit. Nicotine Tob Res 2015;17:127-33.

30. Akl EA, Kahale LA, Agoritsas T, et al. Handling trial participants with missing outcome data when conducting a meta-analysis: a systematic survey of proposed approaches. Syst Rev 2015;4:98.

31. Akl EA, Johnston BC, Alonso-Coello P, et al. Addressing dichotomous data for participants excluded from trial analysis: a guide for systematic reviewers. PLOS ONE 2013;8:e57132.

32. The Nordic Cochrane Centre, The Cochrane Collaboration. Review Manager (RevMan). 5.3. Copenhagen: The Nordic Cochrane Centre, The Cochrane Collaboration, 2011.

33. Adriaens K, Van Gucht D, Declerck P, et al. Effectiveness of the electronic cigarette: an eight-week Flemish study with six-month follow-up on smoking reduction, craving and experienced benefits and complaints. Int J Environ Res Public Health 2014;11:11220-48.

34. Bullen C, Howe C, Laugesen $\mathrm{M}$, et al. Electronic cigarettes for smoking cessation: a randomised controlled trial. Lancet 2013;382:1629-37.

35. Bullen C, Williman J, Howe C, et al. Study protocol for a randomised controlled trial of electronic cigarettes versus nicotine patch for smoking cessation. BMC Public Health 2013;13:210.

36. Bullen C, Howe $\mathrm{C}$, Laugesen $\mathrm{M}$, et al. Do electronic cigarettes help smokers quit? Results from a randomised controlled trial [Abstract]. European respiratory society annual congress; 7-11 September 2013, Barcelona, Spain 2013;42:215s-[P1047].

37. Bullen C, Howe C, Laugesen M, et al. Electronic cigarettes and smoking cessation: a quandary?-Authors' reply. Lancet 2014;383:408-9.

38. Shahab L, Goniewicz M. Electronic cigarettes are at least as effective as nicotine patches for smoking cessation. Evid Based Med 2014;19:133.

39. O'Brien B, Knight-West O, Walker N, et al. E-cigarettes versus NRT for smoking reduction or cessation in people with mental illness: secondary analysis of data from the ASCEND trial. Tob Induc Dis 2015:13:5

40. Al-Delaimy WK, Myers MG, Leas EC, et al. E-cigarette use in the past and quitting behavior in the future: a population-based study. Am J Public Health 2015;105:1213-9.

41. Borderud SP, Li Y, Burkhalter JE, et al. Electronic cigarette use among patients with cancer: characteristics of electronic cigarette users and their smoking cessation outcomes. Cancer 2014;120:3527-35.

42. Manzoli L, Flacco ME, Fiore $M$, et al. Electronic cigarettes efficacy and safety at 12 months: cohort study. PLOS ONE 2015;10: e0129443.

43. Prochaska JJ, Grana RA. E-cigarette use among smokers with serious mental illness. PloS One 2014;9:e113013.

44. Vickerman KA, Carpenter KM, Altman T, et al. Use of electronic cigarettes among state tobacco cessation quitline callers. Nicotine Tob Res 2013;15:1787-93.

45. Harrington KF, Cheong J, Hendricks S, et al. E-cigarette and traditional cigarette use among smokers during hospitalization and 6 months later. Cancer Epidemiol Biomarkers Prev 2015;24:762.

46. Hajek P, Corbin L, Ladmore D, et al. Adding E-cigarettes to specialist stop-smoking treatment: city of London Pilot Project. $J$ Addict Res Ther 2015;6:2. 
Correction: electronic nicotine delivery systems and/or electronic non-nicotine delivery systems for tobacco smoking cessation or reduction: a systematic review and metaanalysis

El Dib R, Suzumura EA, Akl EA, et al. Electronic nicotine delivery systems and/or electronic non-nicotine delivery systems for tobacco smoking cessation or reduction: a systematic review and meta-analysis. BMJ Open 2017;7:e012680. doi: 10.1136/ bmjopen-2016-012680.

The folllowing amendments were considered to the original version of this article.

The following paragraph was added in the 'Strengths and limitations' subheading under 'DISCUSSION' section: 'We usually conduct worst-case sensitivity analysis when there are significant results. However, because we noticed a possible increase in smoking cessation with ENDS (Figure 5) for cessation smoking, we have decided to conduct a worst-case sensitivity analysis to test the robustness of our findings.'

In Table 6,

- The first row should be read as 'Tobacco smoking cessation' instead of 'Mortality' and 'Reduction in cigarette use of at least 50\%' instead of 'Renal insufficiency'. Also, Tobacco smoking cessation refers to OR.

- The header of eighth column should read as 'Relative risk and odds ratio (95\% CI)' instead of 'Relative risk (95\% CI)'.

In table 7 , subheading of the seventh column should read 'Odds ratio (95\% CI)' instead of 'Relative risk (95\% CI)'.

The following footnote is added in both tables 6 and 7:

CI: confidence interval.

In the 'Data synthesis and statistical analysis' section under 'METHODS', the below statement has been added in the $3^{\text {nd }}$ paragraph:

After calculating pooled relative effects, we also calculated absolute effects and 95\% CI. For each outcome, we multiplied the pooled RR and its $95 \%$ CI by the median probability of that outcome. We obtained the median probability from the control groups of the available randomised trials. When it is not possible, we obtained the median probability from the cohort studies. We planned to perform separate analyses for comparisons with interventions consisting of ENDS and/or ENNDS and each type of control interventions with known different effects (no smoking cessation aid; alternative non-electronic smoking cessation aid including NRT and alternative electronic smoking cessation aid (ENDS or ENNDS)). For meta-analyses, we used 6 months data or the nearest follow-up to 6 months available.

The below statement has been added in the Acknowledgements section:

We would also like to thank Dr Aravind Gandhi Periyasamy for bringing these mistakes to our attention in order to issue an erratum rectifying.

Open access This is an open access article distributed in accordance with the Creative Commons Attribution Non Commercial (CC BY-NC 4.0) license, which permits others to distribute, remix, adapt, build upon this work non-commercially, and license their derivative works on different terms, provided the original work is properly cited, appropriate credit is given, any changes made indicated, and the use is non-commercial. See: http://creativecommons.org/licenses/by-nc/4.0/. 
(C) Author(s) (or their employer(s)) 2020. Re-use permitted under CC BY-NC. No commercial re-use. See rights and permissions. Published by BMJ.

BMJ Open 2020;10:e012680corr1. doi:10.1136/bmjopen-2016-012680corr1

(D) Check for updates 